Filo. y Lingüí. 10(2): 63-87, 1984.

\title{
ENTRE LA TRADICION Y LA RUPTURA: MANUEL ARGUELLO MORA, UN HUMANISTA DEL SIGLO XIX
}

María Pérez Yglesias.

"No, lector de mi vida. Se nace poeta y se aprende a hacer versos".

\section{Manuel Argüello (1)}

\section{La historia literaria y la crítica.}

"La literatura abarca, sin embargo, el conjunto de los mensajes escritos que integran una determinada cultura, al margen del juicio de valor que por su calidad merezcan".

\section{Eduardo Galeano (2)}

\subsection{Don Manuel: un lugar en la historia de la literatura costarricense.}

150 años después de su nacimiento (1834-1902)

Son múltiples los tratados sobre literatura costarricense que se han escrito en el país, sobre todo a partir de la década de los 40: textos de historia literaria que buscan, desde distintas perspectivas y criterios -cronológicos, generacionales, por tendencias, corrientes literarias, géneros...sintetizar la vida de nuestra joven cultura.

Con la excepción de La historia de la literatura costarricense de Abelardo Bonilla (3), que pretende escribir la historia literaria desde sus orígenes hasta mediados del siglo $\mathrm{XX}, \mathrm{o}$ de estudios específicos como El costumbrismo en Costa Rica de Margarita Castro Rawson (4), la mayoría de los estudiosos: Rogelio Sotela, Luis Ferrero Acosta, Elizabeth Portuguéz de Bolaños, Virginia Sandoval de Fonseca, Carlos Rafael Duverrán, Alfonso Chase, Seymour Menton, Quince Duncan, León Pacheco, Francisco Ma. Núñez, Manuel Segura, Jorge Valdeperas... manifiestan, explícitamente que sus trabajos no son más que introducciones, resúmenes, prólogos, síntesis, notas para la interpretación de la literatura costarricense o de uno de sus períodos o aspectos. Otros autores estudian el lenguaje de la crítica como Manuel Picado en Literatura, Ideología, Crítica: Notas para una historia de la literatura costarricense (5), los más escriben ensayos o aprovechan sus tesis académicas para analizar textos específicos de la literatura del país. Don Manuel Argüello Mora encuentra un lugar en la mayoría de estos escritos: el de "precursor" o iniciador de la literatura costarricense.

Rogelio Sotela, por ejemplo, lo clasifica entre los precursores - nacidos antes de 1860-y aunque le otorga el mérito de "haber iniciado la literatura criolla, en forma de novela" (6), no incluye sus escritos en la antología porque "las letras costarricenses nacen en verdad .con los hombres que llamaremos de la primera generación" (7). Seymour Menton lo considera "el único viejo de la promoción de 1900" (8). Alfonso Chase afirma que, entre 1860 y 1890 , "se van forjando, en embrión, los primeros brotes de la literatura nacional que culminan con la obra de Manuel Argüello Mora que es nuestro primer escritor, propiamente dicho" (9) y Abelardo Bonilla lo señala como "el primer escritor que emprendió en el campo de la fantasía... y el precursor de la novela costarricense" (10).

Específicamente no existen muchos estudios sobre Argüello Mora como literato; libros sobre historia, derecho, periodismo o educación lo nombran en sus campos respectivos, casi siempre de forma marginal. Abelardo Bonilla y José Marín Cañas hacen un estudio inicial en Obras literarias $e$ históricas y en La trinchera y otras páginas históricas (11), respectivamente. Ambos libros son publicados por la Editorial Costa Rica, en un intento de recopilación de algunos de los escritos de Argüello Mora diseminados en periódicos y revistas o publicados en libros o folletos casi imposibles de conseguir. Eulogio Horta, Blanca Milanés, Justo Facio, Luis Ferrero, Aquileo Echeverría, Alfonso Chase, Gerardo César Hurtado, Rogelio Sotela...(12) dedican breves páginas a su 
semblanza, otros apenas lo mencionan dentro del conjunto.

El balance del estado de la cuestión deja enormes vacíos. Sobre Argüello Mora y sus escritos se ha dicho poco y se ha repetido mucho: las palabras de Abelardo Bonilla o las de Justo Facio, por ejemplo, se encuentran reproducidas innumerables veces (13), la lectura directa de los textos no se refleja en la mayoría de los comentarios y observaciones. Sin que esto equivalga a decir que no existan críticas acertadas.

La intención de este artículo es la de sintetizar, desde una perspectiva intertextual, algunas de las reflexiones que deja la lectura de Don Manuel. Reflexiones basadas en sus ideas, en sus rasgos autobiográficos, en la historia y la cultura de la época que le tocó vivir. Reflexiones y no análisis exhaustivo. Un pequeño homenaje a un hombre culto e inquieto en los 150 años de su natalicio (1834-1902).

\subsection{Historias literarias: criterios y mitos.}

\section{"Al encontrar los nudos claves del tejido de la cultura, el problema no es elegir y adherirse. Lo apremiante es criticarlos, es decir, cruzarlos gracias al texto, con la literatura y sus críticas".}

\section{Manuel Picado (1千)}

\subsection{1 ¿Es literatura? ¿Corresponde a las carac-} terísticas de la novela...?

Las historias literarias, en ge.neral, reproducen una serie de mitos y estereotipos que es necesario develar; las ideas se transmiten y la fuerza de la escritura impide romper con una reproducción irreflexiva y una visión de poder. La ideología de la creación literaria impregna la mayoría de los intentos de crítica literaria -incluso, desde luego, los que se refieren a Argüello Mora-- hay una mayor preocupación por determinar si el escrito es literatura, para-literatura o seudoliteratura, si posee todas las normas para ser cuento, novela o ensayo, que por analizar el texto en sí y la circunstancia que permite su existencia. Muchos se preocupan por decir que Manuel Argüello no es verdaderamente un literato y que su obra no es "exactamente" literatura... ni deja de serlo: "es el creador de la literatura costarricense, más como relación de una anécdota, que como creación propiamente literaria" (15). "Si bien las "crónicas" de Argüello Mora no representan productos acabados de una intención propiamente literaria resultan muy útiles para conocer el estado de nuestra producción finisecular" (16); muchos se interesan por demostrar si lo que él llama novelas lo son verdaderamente, o no cumplen con "los requisitos": "creemos que por la pobreza estructural y el escaso desarrollo de los personajes no pueden considerarse novelas las crónicas noveladas de Manuel Argüello Mora" (17); algunos enfatizan sobre ciertos rasgos biográficos, se empeñan en demostrar sus errores históricos (18) o su veracidad y, con pocas excepciones, allí se quedan (19).

Para comprender la producción de Argüello Mora o de otros que, como éi fueron conservación y ruptura en el siglo XIX, no se puede partir del mito de que la literatura costarricense surge a partir de 1890, ni de que la primera producción del país es realista.

\subsubsection{Literatura oral y popular.}

Se desconoce toda la producción indígena, la tradición oral española y con mayor razón la ladina o mestiza. Se oculta, o apenas se menciona-como en el caso de Abelardo Bonilla, Margarita Castro Rawson, Alfonso Chase o Jorge Valdeperas: "No queremos decir con esto que no hayan existido, una literatura y un arte populares en los períodos anteriores, la hubo, desde luego..." (20)la tradición popular: las canciones de cuna, los poemas amorosos, el canto a la naturaleza, los cuentos de camino, las historias de santos, de animales, de tesoros, de espantos y espíritus, de hadas y misterio, se olvidan los mitos del origen, las representaciones dramáticas, las historias risueñas y las heroicas. Se desconoce el aporte de los negros que trabajan en las plantaciones de cacao en Matina y luego en las bananeras, el de los orientales que se establecen en el Atlántico tiempo atrás, la tradición que traen consigo los españoles y otros europeos y americanos. Si la imaginería en iglesias y portales de nochebuena se desarrolla como un arte, si los utensilios y las joyas de los aborígenes lo constituyen también, ipor qué ignorar o menospreciar la existencia del arte hecho con palabras? La discriminación de lo oral y popular negaría el lugar en la literatura que tienen La llíada o La odisea o los cantares de gesta... La literatura y la escritura no son sinónimos. La cultura oral y popular debe ser valorizada ante la escritura, para destruir el mito de la no existencia de literatura, anterior a la segunda mitad del siglo XIX. 
Si Costa Rica es puente natural entre el norte y el sur y en ella se conjugan la flora y la fauna produciendo una de las maravillas de la naturaleza, también es puente de culturas. Primero los antropólogos, y hoy los lingüistas, intentan recuperar y escribir la literatura oral de los diferentes grupos indígenas, lo que demuestra su existencia y su valor.

\subsubsection{Sin sentido epopéyico.}

Se habla de una carencia de sentido epopéyico, producto de la mitificación de la historia de Costa Rica: pacífica, democrática, igualitaria... Es casi imposible imaginar que las distintas "epopeyas" y conflictos que sufren los costarricenses, no dejen huella en el pueblo: las luchas de los conquistadores contra los indígenas rebeldes, las incursiones a Talamanca, las batallas contra los zambos mosquitos y los piratas ingleses, las revuel tas contra el monopolio del tabaco, los asaltos a las tercenas o ventas de tabaco, los movimientos para impedir que las tierras comunales pasen a propiedad priva$d a$ l los enfrentamientos entre sembradores y ganaderos, las escaramuzas de los republicanos contra los monárquicos, la ley de la ambulancia, la campaña del $56 \ldots$

\subsubsection{Siglos coloniales: "la nada" antes de la} independencia.

Los tres siglos coloniales -con la limitación que trae el aislamiento, la pobreza, la escasez de población, el escaso comercio-no pueden considerarse tampoco nulos, en el plano cultural. Prácticamente todas las manifestaciones que se señalan como literarias en esos siglos son genuinamente españolas, de nuevo se omite la posibilidad de un arte popular y oral... No existen escuelas oficiales, eso es cierto, pero muchos saben leer y escribir: los padres transmiten a sus hijos el conocimiento y los curas forman a los hijos de los hidalgos... son miles los documentos que se producen en esta época y se recogen en los Archivos Nacionales, son varias las bibliotecas particulares en los albores de la independencia. El pueblo-constituido por españoles pobres, criollos, ladinos e indígenas- no sabe leer y escribir, pero participa de la creación como los hidalgos. La tradición cuenta cómo los muleros se detienen en los caminos y pasan, largas horas, contando historias, leyendas, cuentos...

Los dos últimos gobernadores impulsan las escuelas populares y, con la llegada de la independencia, se intensifica el interés por la educación. EI siglo XIX no surge por generación espontánea, es producto de toda una trayectoria colonial con condiciones muy específicas: existe un grupo privilegiado en el plano económico, en el político y aún en el cultural, que aunque no constituye aún, una élite de poder, un grupo dominante, va a ser la base del que se consolida después de la independencia, sobre todo en torno a la producción cafetalera.

\section{El hombre y su época.}

"iQué ganaríamos con tergiversar los hechos o disfrazarlos, ante una posteridad que no tendrá la más ligera idea de nosotros, pasajeros gusanillos fosfóricos..."

Manuel Argüello (21)

\subsection{Cultura integral.}

Según Abelardo Bonilla, y luego Margarita Castro Rawson, todos los esfuerzos de los hombres de la primera mitad y parte de la segunda del siglo XIX, se centran en la formación de un estado: la filosofía, la historia, las leyes y sobre codo la educación y el periodismo son vitales en ese momento: "La preocupación por los problemas de educación social y de fomento económico y la tendencia moralizadora y progresista se manifiestan a través de los voceros de la cultura nacional. El imperativo de organizar la república y sus instituciones monopolizaba todas las energías, eliminando casi del todo la creación poética y dando preferencia a la historia, el derecho y el ensayo" (22). Hay que consolidar una nacionalidad y asumir un poder político y económico, sutil hasta la fecha: "La necesidad de las respectivas burguesías criollas de establecer las bases económicas, sociales y culturales en un proceso tendiente a lograr una identidad nacional se transmitió a la esfera de la creación artística" (23).

Manuel Argüello Mora responde y conjuga estas facetas: reflexiona sobre la vida, se interesa por la historia, estudia derecho y llega a ser juez y magistrado, trabaja en la Universidad de Santo Tomás (profesor y Rector interino), publica constantemente en los periódicos y revistas de la época, participa activamente en la política, y pertenece a la élite privilegiada que se consolida en el país. Es un digno representante de las inquietudes e intereses del momento. Por eso se considera importante dedicar unas cuantas páginas a su pensamiento en 
los distintos campos. Porque antes que abogado, político, historiador, educador y periodista don Manuel es un hombre cul to que quiere estimular la cultura de su patria, y da "rienda suelta" al trabajo, al estudio y a la imaginación.

\subsection{Un siglo cambiante: la consolidación de una élite.}

\subsubsection{La transición al capitalismo.}

Don Manuel Argüello nace, casi como un símbolo, el mismo año que el padre Arista (Vicente Castro) empieza a publicar La Tertulia (1834), uno de los periódicos donde la crítica política y social es más acre y donde se discuten y defienden libertades, como la de expresión. Don Manuel nace, entonces, en una Costa Rica que no es tan pacífica, igualitaria ni democrática, como la describen algunos, pero donde se lucha, en mucho, con la palabra.

Hijo de Toribio Argüello, un abogado nicaragüense, radicado en el país, y de Mercedes Mora, hermana de Juan Mora Porras, queda huérfano de niño bajo la protección de su tío Juan Rafael, quien, por muchos años, dedica sus esfuerzos a sacar adelante hermanos, sobrinos y otros parientes. Este es, quizás, el hecho que marca de forma indeleble su vida.

EI siglo XIX es una época cambiante, donde el asombro cotidiano forma parte de la vida: como Aureliano Buendía en Cien años de Soledad, los vecinos de Rivas se asombran, en 1857, con la traída del hielo: "El almirante hizo traer a tierra cien kilos de hielo, cuya mitad le obsequió a Mora, éste a su vez regaló pequeñas porciones... lo que produjo un gran asombro, pues el hielo en aquella fecha era desconocido en Nicaragua" (M.A.M., p.41). Un siglo contradictorio, ambivalente; un siglo de transición, el paso de un sistema a la consolidación de otro: el capitalista (24).

Un año antes del nacimiento de Argüello, don Rafael de Gallegos emite uno de los decretos determinantes para la evolución posterior de Costa Rica: adelantándose a otros liberales latinoamericanos, declara la necesidad de disolver las tierras comunales y los fondos píos; aunque este hecho tiene antecedentes, es la primera vez que, legalmente, se permite el paso de la propiedad colectiva a la privada. La tierra entra en un proceso directo de comercialización y las condiciones en un país esencialmente agrícola se modifican. El café debe esperar solamente seis años (1840) para alcanzar su vinculación definitiva al mercado inter- nacional, y aquel grupo que había logrado una cierta acumulación de capital a través de las minas, el comercio, o cierta producción agropecuaria: cacao, tabaco, ganado... se abre, a sí mismo, una fabulosa oportunidad. El caso de la familia Mora Porras es ejemplar. Juan Rafael se introduce en el negocio de las minas y del comercio, luego comienza a formar sus haciendas, $y$, cuando el momento se le vuelve propicio, se convierte en uno de los oligarcas del café: tierras y producción directa, beneficios donde se recibe y prepara el grano de los pequeños agricultores, empaque, transporte y venta del producto en el extranjero; con varios socios forma Casas de Comercio (Mora y Aguilar, por ejemplo), únicas a las que brinda apoyo financiero el capital inglés y verdaderos bancos que prestan, a su vez, en Costa Rica. El monopolio es absoluto: tierras, producción, beneficio, comercio, capital financiero $y$, desde luego, ganancia.

\subsubsection{Legalismo y persuación.}

A la par de lo económico, lo político adquiere un valor trascendente: dominar el aparato del estado es fundamental para el grupo. Son épocas de una enorme inestabilidad política, los presidentes se ponen y quitan producto de golpes, confabulaciones, fraudes y dinero. Don Juan Rafael Ilega a ser presidente, en.1849, por dos períodos y aunque es elegido para un tercero, en 1859 se fragua un golpe de estado contra él y se le destierra junto a algunos de sus seguidores - entre ellos su sobrino y adepto Manuel-. Poder político, poder económico.

Los patricios, de esta época, aún con su mentalidad patriarcal, se dan cuenta de la necesidad de tener también un poder educativo, cultural, informativo... y escogen -consciente o inconscientemente, por la razón o la casualidad-conformar un país legalista, un país donde las prácticas de sentido, la educación, tengan peso, aún sobre la fuerza bruta, militar. Escogen el camino de la "persuasión" a través de los medios educativos, de las leyes, la historia, y los medios de comunicación masivos -en ese tiempo el periódico y la revistay no el de la represión, camino donde bregan muchos de los políticos de otros países latinoamericanos, que forman un ejército y compran armas para mantenerse en el poder (25). Persuasión más que represión. Más convencimiento y menos violencia, a pesar del cuerpo militar y de las continuas movilizaciones de presidentes. 


\subsubsection{Consolidación... y ruptura.}

Esta escogencia marca, junto a las condiciones históricas y personales que la permiten, una ruta diferente al país. La educación, la cultura popular, juegan un papel fundamental en esta brecha. Poder político, poder económico, poder ideológico y educativo. La religión, o más bien la iglesia jerárquica, tiene un rol marginal durante la colonia, y aunque acumula poder, en cuanto los políticos lo perciben, tratan de disminuirlo, de permitir la "creencia" como creencia y no como fuerza política y económica; recuérdese toda la reacción anticlerical y la ruptura en el período de don Próspero Fernández.

Don Manuel vive, entonces, la etapa que don Abelardo Bonilla llama período "positivista", cafetalero o "época de formación y consolidación del Estado, (1840-1900), en que las letras están al servicio de las ideas políticas" (26). Vive la etapa que José Luis Vega Carballo marca en dos períodos, el primero "La formación del Estado y la Economía agroexportadora dependiente (1821-1880)" y el segundo "Fortalecimiento de la dependencia externa y la primera crisis agroexportadora y la República liberal (1880-1930)" (27). Porque Don Manuel muere en 1902, a los 68 años de edad.

Un período de consolidación y ruptura. La batalla se da dentro del mismo grupo, las escaramuzas no representan una lucha de clases. El pueblo -español y criollo pobre, y ladinos sobre todo- participa en apoyo a personas, no para lograr sus reivindicaciones. El grupo no se divide en oficial y de oposición (liberales-conservadores) como en el resto de América Latina; aquí se pasa de la oficialidad a la oposición y viceversa, se cambia de grupo con facilidad, porque siempre es el mismo: herencia, matrimonios, familias, padrinazgos...

En la segunda mitad del siglo XIX, los cambios se suceden vertiginosos en la pequeña República; lo que es hoy, mañana es distinto... Del atraso absoluto con relación al resto de las provincias de América Central, se pasa a ser el país más adelantado del istmo y aún de otros países del sur. Las obras de infraestructura se multiplican: puentes, carreteras, edificios, ferrocarril, alumbrado eléctrico, cañería; las escuelas y los alumnos alcanzan proporciones insospechadas, los colegios de segunda enseñanza, la educación para la mujer, los estudios superiores, las bibliotecas, librerías ( a partir de 1860), teatros (Mora o Municipal, Nacio- nal, Variedades)... Las publicaciones aumentan, por ejemplo, un artículo de 1891, señala la existencia de 17 periódicos simultáneos (28). Manuel Argüello describe el cambio en numerosas oportunidades "me refiero a épocas anteriores, cuando la prensa naciente sólo se sentía vivir en la forma de una Gaceta Oficial y en la de alguno que otro periódico semanario, empeñado en desacreditar lo que la Gaceta decía. Es de esperar que hoy no suceda lo mismo, porque no es verosímil que ocho o diez voceros diarios se pongan de acuerdo para ocultar la verdad" (M.A.M., p.33).

Se importan artículos, hasta ahora desconocidos y suntuarios, la moda irrumpe y el consumo se propicia. Los viajes se convierten en una de las actividades obligatorias de la clase dominante. EI cambio es demasiado rápido y lleno de contradicciones, las viejas y las nuevas estructuras coexisten, luchan, se toleran.

\subsubsection{Imitación y "apariencia".}

La imitación está a la orden del día, como una manera de afirmación: se copian los estilos europeos y aún norteamericanos, se pretende ser como allá... se compara, se establecen distancias y de nuevo se imita... Se quiere lo ajeno, lo exótico y se defiende lo propio, lo criollo. Incluso, la primera afirmación escrita de lo popular, de lo nacional, se hace con cánones extranjeros: el costumbrismo sigue, con salvadas excepciones -el estilo de los españoles y otros latinoamericanos como Larra o Proaño-, el romanticismo aparece, un poco trasnochado y decadente. Darío, Martí, Gavidia, importan el modernismo que también influye aunque renace con mayor fuerza en los principios del siglo venidero.

La picaresca del siglo XVI, se ve representada de manera singular por don Manuel, en su Huerfanillo de Jericó; las novelas de intrigas, de misterio, folletinescas también encuentran sitio en su obra. Los Episodios Nacionales de Pérez Galdós están presentes en las "novelas históricas": Elisa del Mar, La Trinchera o Margarita... El naturalismo se evidencia en El martirio de una niña de cinco años en Matina (29). La naturaleza exuberante de la América Latina, ya explotada por autores del sur, es motivo de descripciones e identificación en varias de las obras del autor. La observación de don Abelardo de que existe "un escasísimo interés por la naturaleza que no ofrece motivos interesantes porque en ella vivía cotidianamente el escritor. Los litorales del Atlántico y el Pacífico vinieron a 
constituir la novedad y la variedad, pero solo han sido descubiertos para fines estéticos durante los últimos años" (30), pierde validez ante la lectura de los textos de Argüello Mora y algunos de sus contemporáneos.

Epoca de imitación y afirmación de la personalidad costarricense, época de apertura y conservación de la tradición, época de lo nacional y lo distinto, de ignorancia y cultura. Argüello es consciente de la tendencia a la burda imitación y la rechaza: "ser un mono que imita lo que ve, es el mayor defecto que puedo concebir" (M.A.M., p.48), es consciente del interés de cierta clase por parecer cultivada y critica "Ia apariencia", la superficialidad, los "títulos" adquiridos en pocos meses, y el juego social-amistades, parentescos y padrinazgos - que emula al mediocre: "don Cupertino vivirá y morirá Doctor, como pretenden vivir y morir tantos poetas, literatos, escritores in partibus in fidelium, que apenas son escribientes, escribanos, o literatos a la fourchette" (M.A.M., p.375). "Letrado de pocas letras, abogado que jamás ha dirigido ni abogado por nadie, y jurisconsulto que no acostumbra consultar más que consigo mismo, ha logrado sin embargo ocupar los más altos puestos en los tribunales de justicia" (M.A. M., p. 382) "Cascajal creía su educación incompleta mientras no abriera en persona el gran libro del mundo, viajando por la vieja Europa" (M.A.M., p.412)... tres meses. "Ya listo para la vuelta a América pasó a un almacén de libros de ocasión y compró un lote de trescientos volúmenes por cien francos" (M.A.M., p.413). El criado Zoilo basa su prestigio en conocimientos superficiales que convencen al más ignorante: "Ese diablo de Zoilo es cobarde y borrachón, pero no se puede negar que es muy leído y sabido" (M.A.M., p.434).

\subsection{La posibilidad de educación formal.}

Las familias privilegiadas son pocas. Hasta esa segunda mitad de siglo, se empiezan a perfilar oportunidades educativas y de cultura para otros que no forman parte de la élite... comienzan a formarse individuos que no pertenecen directamente al conglomerado cafetalero o comercial pero que tienen un modus vivendi que les permite, pobremente, asistir a la escuela y demostrar su interés académico... Argüello Mora "refleja el punto de vista de una oligarquía cafetalera inmersa en sus contradicciones, preocupada por pequeños detalles, anécdotas triviales, en oposición a los nuevos escritores que aparecen a principios de siglo originarios los más de familias campesinas, 0 desarraigadas, de la gran oligarquía costarricense" (31)

Recuérdese que, aunque la primera Casa de Enseñanza Pública se funda en 1813, con el Bachiller Osejo, y luego las escuelas se multiplican en el Valle Central y otras regiones, hasta 1840 la posibilidad de hacer estudios superiores sólo la da, con pocas excepciones, la Universidad de León de Nicaragua. En 1844, José Ma. Castro Madriż funda la Universidad de Santo Tomás -clausurada por Mauro Fernández en 1888-, que prácticamente funciona con la cátedra de Derecho y los estudios "secundarios" ( surgen el Instituto Nacional y luego el Instituto Universitario adscritos a ella), para realizar otras carreras es necesario salir del país. Muy temprano se funda la Escuela Normal en San José cuyo requisito de entrada son, apenas, las primeras letras. A partir de 1840, la Universidad de San Carlos de Guatemala sustituye, en cierto sentido, a la de León, lo que implica una mayor influencia liberal, y, a partir de 1860, Inglaterra y otros lugares de Europa abren mayores posibilidades (32). Claro que hay excepciones, ya en 1840 , viene graduado el primer costarricense educado en Europa (Inglaterra), don José María Montealegre.

Don Manuel Argüello estudia las primeras letras en casa y, según él mismo refiere en su artículo El primer colegio, a los nueve años ingresa en el primer internado del país (33); el colegio del padre Paúl de Heredia. Argüello lo describe -como muchos relatos europeos de la época-como poco menos que un "presidio", Ileno de discriminaciones, malos tratos y peores comidas, mezclados con libros e informaciones. En otro de sus relatos, se refiere a un colegio inglés donde la ganancia constituye también el baluarte de la enseñanza, con la diferencia de que el costarricense es un colegio dogmáticamente cristiano representado por la figura del padre Paúl, y el colegio europeo lo regenta un "inglés metalizado y con ribetes de luterano antipapista" (M .A.M., p.164).

Educado con la fuerza del castigo y la memoria, Manuel pasa a la Universidad de Santo Tomás donde cursa estudios intermedios, se gradúa de Bachiller en Filosofía, en 1850, y de Licenciado en Leyes, en 1853. Más tarde su padrino-ya presidente- le envía a la Universidad de San Carlos de Guatemala; allí trabaja en varios bufetes y viene graduado con honores como Doctor en Derecho, poco antes de que se inicie la segunda campaña nacional (1857).

Desde pequeño Argüello Mora ama la lectura y 
aprovecha todos aquellos ejemplares, de muy diversa índole, que tiene oportunidad de conseguir Muy joven aún, incursiona en el campo de la escritura, pronto empiezan a publicarse - a menudo sin firma o con un seudónimo- distintos artículos en periódicos y revistas.

\subsection{El exilio.}

\subsubsection{Un golpe de estado en 1859 .}

Recién Ilegado de San Carlos, Manuel, con apenas 23 años, colabora intensamente con su padrino. Muchos le atribuyen la redacción de "partes de guerra" (34) y otros discursos del presidente.

Abogado como su padre y como muchos otros de la época, en el momento de su regreso es nombrado Juez de primera instancia de San José, cargo del que luego dimite para dedicarse a menesteres más políticos: "acababa de recibirme de abogado en Guatemala. Aunque más duro para ser triturado por los enemigos de Mora, era más sensible a sus golpes tanto por mi extrema juventud (22 años), cuanto por ser sobrino carnal del gobernante, $y$ en realidad su hijo adoptivo, y a quien yo le debía todo: educación, profesión y el cariño de un padre" (M.A.M., p.64).

Sólo dos años disfruta el poder al lado de don Juan Rafael. Este, cafetalero y oligarca, humano y patriarcal, rico y sencillo, decide - para algunos por rencillas personales y para su propio beneficio y para otros por ayudar a los pequeños agricultores (35) - fundar el Banco Medina y romper con el monopolio financiero de las casas comerciales. Esta y otras medidas provocan el golpe de estado (Juan Rafael y su socio y amigo Vicente Aguilar. tienen un serio problema legal--cuestión Mora y Aguilar (1861) (36) - y este último encabeza, subrepticiamente el golpe de 1859).

Presos y desterrados, aún cuando se garantizan sus vidas y bienes, deben salir del país pordecreto: "40 - Para la completa tranquilidad de la Nación, el presidente nombrado hará salir inmediatamente del territorio a los señores Juan Rafael Mora Porras, don José Joaquín Mora, don José María Cañas y don Manuel Argüello...." (M.A.M., p.66). Sólo cuatro individuos, aquellos que se consideran más peligrosos son nombrados: el héroe presidente del 56 y sus generales Mora y Cañas... Mucho debe haber trabajado en política el joven abogado para que lo cuenten entre los proscritos: "Heme allí colocado y convertido en un personaje histórico....
¿Cómo puede concebirse que a un muchacho de 22 años se le trate y considere al nivel de hombres tan superiores como los Generales Mora y Cañas...? se me hizo sufrir, no unos días, ni meses, sino años de indeterminado destierro" (M.A.M., p.66). "No hay que olvidar que para don Francisco María Montealegre era una realidad la leyenda inventada por mis enemigos, quienes me suponían una inteligencia depravada y diabólica empleada en dirigir por torcidos caminos al señor Mora y su gobierno" (M.A.M., p. 73 (nota)).

\subsubsection{El gran libro del mundo.}

El decreto se convierte en la realidad de un sueño: viajar y viajar... Las circunstancias son desfavorables y no lo son: salir proscrito, sin esperanza de vuelta, en compañía de aquel a quien más ama retirado de su poder, le hace sentir añoranza de patria: "Durante cuatro años arrastraré por extranjeras regiones la incurable nostalgia por cuanto en la tierra me era caro" (M.A.M., p.66) "iCosta Rica! iQué hermoso, qué pintoresco y delicioso rincón de flores nos pareces cuando te contemplamos lejos... Costa Rica en esas circunstancias se nos convierte en un paraíso terrenal, y el resto del mundo lo vemos como una comparsa cuya existencia nos es indiferente" (M.A.M., p.454). Llegar a Europa y a Estados Unidos como perseguido político tiene un cariz diferente $y$ un interés distinto para los que lo reciben, "allí es incompatible -afirma don Manuel- la nulidad con el ostracismo" (M.A.M., p. 67).

Protegido del presidente de una pequeña nación que defiende su libertad contra los filibusteros, Argüello recibe invitaciones para asistir al teatro, a círculos políticos y literarios, para compartir y comentar las circunstancias del exilio. "Atormentado desde muy niño por un deseo irresistible de viajar... tuve la buena fortuna de que el destino complaciera mis aspiraciones sin obligarme a forzar los acontecimientos... joven aún, varios destierros del suelo patrio me proporcionaron la ocasión de viajar" (M.A.M., p.439).

Los viajes considera Argüello "son indispensables para completar la educación científica, artística o simplemente comercial" (M.A.M., p.450) no se arrepiente de haber seguido su "natural" inclinación al estudio y a los viajes (M.A.M., p.440) y aconseja seguir su ejemplo, a la juventud de la época. Cinco años de viajes en exilio y muchos otros, por motivos diversos, "un negocio, una enfermedad... me presentaba como pretexto para 
alejarme de estas playas" (M.A.M., p.439) o el simple placer de conocer y aprender. Vive en Estados Unidos del Norte y en Europa (Italia, Francia, Holanda, Inglaterra, Irlanda, Bélgica, Suiza, Alemania, Rusia, Grecia); conoce Colombia y los otros cuatro países de la América Central (M.A.M., p.450).

Sus viajes le permiten aprender en la práctica, leer, conocer las ideas políticas, literarias y culturales del momento; le permiten apreciar la "estandarización" de las ciudades y las clases altas que impone la "civilización" en los diversos países, entender que las particularidades están en el pueblo: "No basta conocer las capitales y las muchedumbres que las habitan... La gente llamada decente en todas partes es la misma. La civilización ha nivelado todo en esa clase... Los grandes contrastes, las costumbres verdaderamente nacionales deben buscarse en las muchedumbres, esto es, en el pueblo de los campos, de las provincias y aldeas" (M.A.M., p.451). En el extranjero, toma distancia de su patria, compara su atraso y sus valores; percibe las diferencias de clase dentro de cada país: "¿En cuál Universidad se aprende a sentir y a pensar, lo que se siente y piensa ante el espectáculo de una clase de hombres que viven hastiados de los placeres que les proporciona la opulencia, al lado de los que mueren de hambre y de frío porque les falta lo indispensable?" (M.A.M., p.440). Toma conciencia de las distancias económicas entre un país y otro: "Todo el mundo se pasea feliz en este país extraordinario (Holanda). Ni mendigos ni esas caras desoladas por el hambre y el sufrimiento, como son tan comunes en Francia, España e Italia" (M.A.M., p.461). Fuera del país percibe las dicotomías en boga "civilización y barbarie", "nacional y exótico", "semejante y diferente".

Reconace las cualidades de cada pueblo, su esfuerzo y trabajo, su cultura; entiende las diferencias entre los hombres, se horroriza ante la represión y dominio bajo el que viven los italianos, gobernados por el imperio Austriaco y los irlandeses sometidos por Inglaterra: "los ingleses rodeados de un lujo oriental insultan la miseria de sus siervos o cuasi esclavos que riegan el suelo irlandés con el sudor de su frente y las lágrimas de sus ojos" (M.A.M., p.49); vive los contrastes de la América del Norte, práctica y metalirada, se da cuenta de las intenciones intervencionistas de los Estados Unidos que desean desplazar el dominio Europeo (M.A.M., p.44). Admira y compara sus mujeres.

Se entristece y asombra del nulo conocimiento que hombre y libros tienen de su pequeña república: "Sí, me dice, yo sé donde está; es una isla de las Antillas... El papá... sacó de su bolsa un Almanach de Gotha... Costa Rica uno de los estados de Guatemala, el más pobre de ellos. Capital, Cartago, ciudad episcopal" (M.A.M., p.461) "Costa Rica o Puerto Rico que es lo mismo... colonia española poco próspera..." (M.A.M., p.244).

Viajar le posibilita conocer el francés, el inglés, un poco el italiano, lenguas que le permiten leer originales aún no traducidos. Manuel Argüello es consciente que puede realizar su sueño y vivir el exilio en forma decente, gracias a su "pequeña fortuna"; en una de sus impresiones de viaje asegura que gastó "algo más de treinta mil pesos" (M.A.M., p.439), sin ganar nada. Se cuestiona si valió la pena hacerlo y estar, ya viejo, subordinado al "trabajo y en la dependencia de algún cargo público, que me brinde el pan de cada día" (M.A.M., p.440) y llega a la conclusión afirmativa: estimula a los jóvenes a salir e incluso, da fórmulas de viajes económicos (M.A.M., p. 452).

Ningún libro puede brindar el placer y el conocimiento de ese gran libro que es para él, el mundo (M.A.M., p.450). La cultura, la arquitectura, las leyes diferentes, los sistemas políticos distintos, el folklor $y$ arte de cada pueblo, los conciertos musicales, el ballet, el teatro, las grandes bibliotecas y librerías, las corrientes filosóficas, científicas, literarias, artísticas, las informaciones periodísticas...

\subsubsection{La epopeya de 1860: un pueblo dividido (37) y el destierro a perpetuidad.}

Argüello regresa a Costa Rica en 1860, junto a Mora y Cañas, con el propósito de recuperar el poder: "Estaba en mi pleno derecho de insurrección contra un gobierno de hecho, y con la obligación y la voluntad de acompañar a Mora... colocados fuera de la ley que nos negaba su amparo y protección, se nos puso en la necesidad de prescindir de ella y de reconquistar, aún por la fuerza, una patria y un hogar" (M.A.M., p.70). Juan Rafael, estimulado por los moristas que quedaron en el país, llama a Manuel -en Irlandapara que lo acompañe en su gesta: "Vente por el primer vapor, te necesito con urgencia. Tiempo tendrás después para viajar y filosofar. Tuyo. Juan Rafael Mora" (M.A.M., p.50). El desembarco, la traición en el territorio, la lucha de "hermanos contra hermanos" (M.A.M., p.68), la batalla de la 
Angostura y en varios puntos de la provincia de Puntarenas, los refuerzos interceptados, la prisión, un indulto que no llega a tiempo y el fusilamiento de Mora y Cañas, sus héroes, sus amigos, su familia... Un episodio épico y sentimental que vive y perdura en sus actos y en sus textos.

Manuel Argüello escribe sus Páginas de historia, sus "novelas históricas" en torno a la figura de don Juan Rafael y la suya propia. Escribe como testigo y actor desde la perspectiva de sus años maduros: "Si mis recuerdos me indujerän en error, espero me sean tenidas en cuenta, en cualquiera de las faltas de exactitud, la buena fe con que arrastro el difícil papel de testigo presencial de hechos importantes, pero que han tenido lugar treinta y cinco años hace, $y$ que por consiguiente puedo al retratarlos, incurrir en alguna confusión de nombres, de fechas o de personas..., (M.A.M., p.99), cuántas noches pensando en cada uno de los acontecimientos, cuántas discusiones, cuántos sueños e idealizaciones desde el segundo exilio (1860-1863). Ricardo Fernández Guardia en Cosas y gentes de antaño, transcribe una carta del General en Jefe del Ejército de operaciones, del primero de octubre de 1860: “...da cuenta de haber sido pasados por las armas don Juan Rafael Mora e Ignacio Arancibia, y sentenciados a deportación don José María Cañas, don José Joaquín Mora, don Manuel Cañas, don Manuel Argüello y don Leonidas Orozco" (38). La magia del tiempo deja su huella y el amor filial la suya. Manuel expresa, como lo hace Bernal Díaz del Castillo al empezar su Historia verdadera de la Conquista de la Nueva España (39), inquietudes y propósitos muy semejantes: ambos son testigos y actores, escriben los hechos mucho tiempo después de transcurridos, muestran erudición y falsa modestia -porque reconocen y conocen sus méritos innumerables veces; ambos reprochan a aquellos que, sin haber vivido ni conocido, se atreven a escribir falseando hechos, $y$, los dos quieren decir la verdad, solo la verdad, por ello se disculpan - de antemano-por cualquier falta de su memoria. Es curiosa tanta coincidencia de criterios y presentación.

\subsection{El polifacético ideólogo de la clase domi-} nante.

\subsubsection{Las componendas políticas.}

Después de varios años de exilio -en principio perpetuo- la insistencia de los "moristas" y amigos de la oposición, deciden a los Montealegre a firmar el indulto y Manuel Argüello regresa al país, en 1863. Casi inmediatamente, "sus enemigos" lo llaman a conversaciones para "tranzar" sobre un nuevo presidente. Argüello afirma que, a su regreso a San José, se convierte en el líder de los seguidores de Mora "-ya en aquella época tenían un jefe (perdón por la inmodestia pero la verdad ante todo)" (M.A.M., p.90)- y es quizás por esa razón, que deciden tomarlo en cuenta en las componendas políticas para llevar a la presidencia a don Jesús Jiménez, con quien colabora y a quien considera un "buen" gobernante: "nos hizo gozar en 1863 a 1866, de uno de los raros períodos de paz, de orden y reconstrucción política" (M.A.M., p.74).

\subsubsection{De católico a masón.}

Católico por tradición, liberal por estudio e influencias, funda junto a su suegro, don Leonzo de Vars y otros hombres "progresistas" la primera logia masónica del país (40). En ella tiene oportunidad de "hermanarse" con grandes personalidades liberales de la época, quizás el más importante para él, el doctor José Ma. Castro Madriz. La tradición cristiana pesa y la masonería encauza sus ideas. En sus textos aparecen continuamente citas bíblicas, interjecciones religiosas y alabanzas a sacerdotes hermanos- "el dignísimo presbítero don Antonio del Carmen Zamora" (M.A.M., p.76) - o a labores humanitarias: "me dedicaré al alivio de la humanidad doliente. Seré Hermano de Caridad" (M.A.M., p.147). Al lado de todo esto aparecen, críticas acres y satíricas a otros representantes de la Iglesia: el Padre Fernández "a quien Ilamaban el Padre Enanito, fenómeno ridículo y sacrílego, que trajo el ejército en calidad de capellán" (M.A.M., p.76). El cuadro de costumbres Mi cuñado el cura (M.A.M., p.414) resume todos los vicios colectivos y particulares de un "tipo" de sacerdote: el Padre Estafas y Pamplinas. La admiración o condena, se refiere -en general- más al hombre, que a la función eclesiástica que cumple.

\subsubsection{La familia Argüello de Vars .}

A su regreso de Europa se casa por la Iglesia con Mariana de Vars Castillo, importante entronque político-económico, y tiene varios hijos -Manuel, Mariana, Juan Rafael y María Luisa- (41). En el artículo La Elección del doctor Castro señala cómo la muerte de otro de sus pequeños lo hace 
alejarse por un tiempo de la política (M.A.M., p.108). Manuel, su hijo mayor, muere en un duelo con Joaquín Tinoco a principios de siglo: "Don Manuel Argüello de Vars fue su hijo, y precisamente murió joven... en un duelo. Yo lo conocí de niño - dice Marín Cañas-pero apénas lo recuerdo. A su señora y sus hijos e hijas, sí los conocí por haber tenido su residencia cerca del colegio "Evans" (42).

\subsubsection{Campañas políticas, trabajo protesional y cargos públicos.}

Ideólogo de la clase dominante -en el poder o en la oposición- Argüello Mora no tiene que esperar mucho tiempo para ocupar cargos de privilegio. La política lo apasiona y trabaja activamente en las campañas electorales, en la defensa o descrédito del gobierno a través del periodismo, ocupando cargos públicos -Cartera de Obras Públicas, Ministro de confianza de Tomás Guardia en la Secretaría de Fomento (M.A.M., p.109)-, como colaborador cercano de los hombres públicos -Juan Rafael Mora, Jesús Jiménez, José Ma. Castro Madriz, Próspero Fernández...- o simplemente con un "juego político entre telones".

Trabaja como abogado en un bufete -en algunos períodos más intensamente que en otros-, y escribe una buena cantidad de documentos jurídicos, los más célebres La Cuestión Mora y Aguilar; ocupa el cargo de Juez de primera instancia de San José, el de Magistrado de la Corte de Casación (1864) y el de Ministro de Gracia, Justicia y Fomento de la República de Costa Rica (43).

En el campo educativo imparte, en la Universidad de Santo Tomás, varios cursos de derecho, y llega a ser Vicerrector y Rector interino (1865) en sustitución de José Ma. Castro Madriz, quien mantiene la rectoría en períodos al ternos, casi diez y siete años (44).

El criterio legalista de autoridad, la experiencia en el campo jurídico, se manifiestan en sus textos; la ironía recae, muchas veces sobre el "picapleitos", el "abogadillo" mediocre, el sinvergüenza: Mi primo el Licenciado Cascajal (M.A.M., p. 410), Los bienaventurados (M.A.M., p. 382). Un abogado de fin de siglo (M.A.M., p. 375)... En otros artículos, por el contrario, valoriza al "abogado que aboga y al jurisconsulto que consulta".

\subsubsection{Agricultor y comerciante.}

Además de su trabajo político, el educativo y el profesional, Argüello acomete varias empresas de agricultura (1869) y prueba fuerzas en el comercio (45); en su novela El Huerfanillo de Jericó, nombra la Hacienda Nueva Corinto en la Zona Atlántica y su labor dentro del campo de la justicia: "Ve a Nueva Corinto, a aquella finca de don Manuel Argüello..." (M.A.M., p. 138) "Pedrito, esta hacienda fue de un señor que tiene algún mando en Justicia..." (M.A.M., p.136). La casa de la hacienda, "construida en Nueva York y armada aquí" (M.A.M., p.128) alberga al protagonista que trabaja, sin éxito, como cargador de banano.

Al comercio se dedica importando artículos, que luego vende en su Bazar Atlántico, la tienda es descrita por Magón en el cuento "La guerra franco-prusiana". Todavía en febrero de 1910 allí estaba, tal cual fue en 1871, el local que contenía todas las maravillas del Bazar Atlántico, de don Manuel Argüello Mora, a cincuenta varas al norte de la esquina Noroeste de la Plaza Principal.. icuántas cosas lindas había detrás de aquellos vidrios!" (46). "El bondadosísimo don Manuel me escuchó con gran paciencia..." (47).

\subsubsection{El culto al libro y al espectáculo.}

Don Manuel, a través de sus viajes y contactos, logra formar una excelente biblioteca particular, $y$, en 1870 decide abrir al público un comercio con características muy especiales "una librería, no para vender sino para alquilar obras a precios muy bajos: mal negocio pero contribución efectiva a nuestra cultura" (48); estimula a los jóvenes a leer, les presta sus libros e incluso, se hace cargo de la Biblioteca de la Universidad de Santo Tomás para abrirla al público (1884): "poseía la Universidad de Santo Tomás una biblioteca bastante numerosa, pero no se había abierto nunca al servicio del público; consiguió que se pusiese bajo su custodia; abrió a los pocos lectores de aquellos días las puertas del local en que la biblioteca se hallaba, costeó la luz y se convirtió en bibliotecario ad honorem" (49).

Ama el teatro y la música y no se pierde ninguna de las actividades que se presentan en San José (o en el extranjero); escribe un artículo sobre la soprano Adelina Patti a quien conoce en Estados Unidos, y otro sobre Luis Humboldt, un muchacho alemán que toca el piano (M.A.M., p.471 y 478). 
En oportunidades se refiere a la música y las canciones costarricenses: "La letra de la canción fue compuesta en San Ramón en 1881, por el joven costarricense don David Hine y la música por el malogrado artista Manuel Gutiérrez" (M.A.M., p.237).

\subsubsection{Retrato de fragmentos.}

Blanca Milanés (50), Justo Facio y Aquileo Echeverría dan algunos rasgos de su carácter: estudioso, amante de la lectura, el arte y la política; inteligencia pronta y perspicaz; temperamento nervioso y activo; inestable en sus quehaceres, polifacético y emprendedor. De contextura débil, erguido, afectuoso, pequeño de estatura $y$ paso firme. Elegante, siempre con sombrero $y$ bastón con punta de oro, perspicaz y con un fino sentido del humor. A veces ingenuo y sencillo, siempre ágil interesado en los niños, y en conocer, siempre conocer.

\section{Intertextualidad y juego de predominios.}

"La intertextualidad, definida como 'interacción textual que se produce en el interior de un solo texto', no se refiere, entonces, a la red de influencias que se buscan siempre en la literatura, ni siquiera a la simple interrelación de diferentes textos escritos: su apertura es mayor y abarca el texto general de la historia y la cultura".

\subsection{Lengua y lectura.}

Si se parte de la noción de literatura como texto, y el texto como práctica - no como inspiración divina o genio creador-, es fácilmente explicable el interés que todos estos intelectuales del siglo XIX, tienen por la cultura integral.

Un texto es una práctica social, un trabajo, una producción. El texto como productividad es trabajo de redistribucion del orden de la lengua e intertextualidad (52).

El instrumento vital con que se trabaja el texto es, entonces, la lengua, y para utilizarla hay que conocerla y dominarla. Quizás por eso los esfuerzos del siglo se centran en la educación, y como uno de sus ejes principales, en el estudio del lenguaje: "Al aislamiento general de la Colonia sucede un aislamiento relativo en el lenguaje. El costarricense entre 1821 y 1890 no hace literatura, construye de muchas maneras, un aparato general educativo" (53). A fines del siglo se establece toda una polémica en torno al lenguaje popular/lenguaje erudito y se fija una política para afirmar la lengua: "Para terminar con las irregularidades, en 1883, el gobierno de Costa Rica decidió uniformar la ortografía de la República" (54).

Todo texto como intertextualidad, integra los textos anteriores y sincrónicos, y, surge como afirmación o negación de otros textos. Para construir textos hay que conocer textos, de ahí el enorme interés que se tiene en la época por la lectura, por el conocimiento de lo escrito... de los países extranjeros, de las normas y el pensamiento de la actualidad costarricense: "Antes que creador, artísticamente, el costarricense fue un admirable lector, un devorador de las culturas europeas..." (55).

Ya en 1832, se emite la primera ley republicana que restringe la exportación de libros "opuestos al dogma", "lo que por reflejo nos informa que la introducción de libros de todas las ideologías empieza a intensificarse... La gente cada vez lee más... trata de imitar a Europa en sus formas de vivir y consumir..." (56).

La Imprenta llega a Costa Rica en 1830 y el periodismo alcanza durante el siglo, proporciones casi inverosímiles (57). Los círculos políticos, las tertulias, las reuniones informales para tratar asuntos diversos son cotidianas. Las imprentas y las ediciones se multiplican. La polémica, la controversia, la crítica -sátira, irónica, humorística- se convierte en pasatiempo y formación diaria. Así el conocimiento se consolida a través de la lengua, los libros, la discusión, lo propio y lo ajeno.

\subsection{Realismo: ¿negación del texto romántico?}

Para la gran mayoría de los investigadores, la literatura costarricense surge con el realismo, que - para Abelardo Bonilla y otros críticos que lo reproducen- "no fue una liquidación de una corriente literaria, sino un movimiento inicial, un punto de partida" (58).

La producción romántica costarricense se desconoce o minimiza: "el imperativo de organizar la República y sus instituciones..., monopolizó todas las energías... aisló al país del movimiento romántico y eliminó, casi del todo, la creación literaria" (59). "Las letras costarricenses, retrasadas en los 
siglos anteriores..., hasta ignorar del todo el movimiento romántico..." (60); se olvida toda una producción representada por La Lira Costarricense (61) y el mismo Manuél Argüello Mora. En un trabajo elaborado como tesis de licenciatura, aún inédito, el profesor Napoleón Pizarro Centeno analiza la obra de Argüello Mora y la clasifica como romántica: "Con base en lo expuesto... en esta tesis, se ha demostrado, de manera indubitable, que Argüello Mora desarrolló plenamente en nuestras letras un "modelo literario romántico" (62). Ya algunos estudiosos habían señalado esta característica: Mary Clara Allison analiza, parcialmente, la novela Misterio (63); Ernesto Castegnaro comenta Margarita, novela que "siguiendo la fórmula... del romanticismo combinó una trama, sentimental y un episodio histórico" (64) y José Marín Cañas, clasifica la obra como "romántica y de recuerdos" (65) anterior al "realismo" que se iniciara en el 900... (66); pero en todos los casos se hace referencia a un texto particular (Allison, Castegnaro) o a un "sentido romántico general" (Marín Cañas).

Con fuerte influencia romántica, Argüello incluye tramas folletinescas mezcladas con hechos históricos, donde las circunstancias familiares, económicas, de compromisos anteriormente adquiridos, o las "jugarretas" del destino, nublan o dificultan el amor. "Elisa del Mar" termina en el convento y Alberto Villalta, su enamorado, muere en Colombia, en un duelo, porque no le interesa vivir. Julio Valera y Ester Montealegre pertenecen, como Romeo y Julieta, a grupos antagónicos, Julio muere en manos de su rival y Ester Ilora su destino (La trinchera); las gemelas del Mojón, enamoradas del mismo hombre finalizan, una muerta y la otra loca (Las dos gemelas del Mojón); Manuel Barrientos y Rosa Salas se casan luego que Manuel sale de la cárcel, una vez que Jaime Campos se arrepiente y confiensa (Un drama en el presidio de San Lucas). En La bella Herediana después de numerosas aventuras y una truculenta historia, los hermanos Elena y Rafael, de origen campesino, se casan con los jóvenes "distinguidos" Jorge Palacios y Mercedes Almagro. Margarita y Jorge se aman pero Ricardo, amigo del primero, se interpone, mata a Patricio y culpa a Jorge, al final los amigos se pelean $y$, herido mortalmente, Ricardo confiesa; más tarde los primos se unen (Margarita). Mistterio, aún más compleja e inverosímil tiene un final semejante... un drama doloroso confronta muchas vidas que al final llevan al amor o a la locura. Abundan los due- los, los crímenes, los secretos de familia donde los novios resultan hermanos, los cambios de niños en la cuna, los amores no compartidos, el triángulo amoroso. Argüello logra mantener el interés por la intriga en algunos momentos, pero el exceso de acontecimientos, de disgresiones rompen el hilo principal; un caso ejemplar es su novela Misterio. La casualidad está siempre presente: el suspenso y la intriga, ocupan un lugar dentro del texto. La visión de mundo es a veces tremendista, otras sarcástica, triste o angustiosa.

La actitud romántica corresponde, no solo a la "imitación" de una corriente literaria en boga, sino también al sentido general de la época: consolidación de "libertades" y nacionalismo. No se trata de discutir si los escritos costarricenses están "a la altura" de los textos románticos del mundo o no, lo importante es que Costa Rica se integra también al movimiento y tiene sus representantes.

Así, el realismo no es un "punto de partida"; surge como la negación de un texto romántico y como afirmación de ciertos rasgos que vienen gestándose y definiéndose dentro del costumbrismo y el ensayo periodístico.

Si es imposible definir líneas "puras" - realismo, naturalismo, costumbrismo, romanticismoen épocas posteriores, con mayor razón lo es, cuando se trata de una literatura incipiente. Cada escrito literario -como intertextualidad-conserva elementos de tendencias anteriores y perfila otros, cuya reafirmación es posterior. Existe un juego de predominios, no de "absolutos".

Don Manuel reconoce su carácter híbrido y, los críticos enfocan dentro de su producción numerosas corrientes y tendencias - que predominan o se combinan en uno $u$ otro texto-.

\subsection{La sátira social y el costumbrismo.}

En numerosas oportunidades los críticos afirman el carácter costumbrista de la obra de Argüello Mora. Elizabeth Portuguez lo presenta como "Uno de los primeros en escribir sobre temas de actualidad son sátiras de costumbres y a la sociedad" (67). Margarita Castro le dedica varios párrafos de su estudio, y resume varias de las características del costumbrismo que don Manuel refleja en su obra: "Simplicio Cucufate es el seudónimo utilizado por uno de los iniciadores del costumbrismo... en una serie de ocho cuadros..." (68).

Muchos de los "defectos" y las "virtudes" que la crítica señala a don Manuel, corresponden al 
costumbrismo de la primera época: "La pobre organización, las disgresiones sin motivo, el tratar dos o más temas en un solo artículo, la poca confianza en su poder creativo..." (69); "la mezcla o fusión del costumbrismo con la política" (70), "la sátira y el estilo epistolar..." (71);"la intención moralizadora..." y "el propósito docente" (72). Manuel Argüello "pinta una serie de 'tipos', a través de los cuales se describe, satiriza o comenta toda una clase sociológica, social, profesional o local. Tal es el caso de una serie de cuadros que aparecen en Costa Rica I/ustrada de 1887 a 1888" (73). La "leyenda" es otro de los temas favoritos de los costumbristas, don Manuel describe - "La \|orona", "La Sonámbula del Pirro" o "El pozo de la Sirena..." "con otra interpretación, ya cuanto a la trama ya en cuanto al desenlace" (74).

El autor utiliza temas, personajes, costumbres, acontecimientos y paisajes costarricenses, solo el lenguaje se mantiene erudito -con los desequilibrios gramaticales propios de la época-; párrafos largos y empleo de numerosos recursos retóricos, citas históricas, bíblicas, mitológicas y, numerosas palabras en otras lenguas (latín, francés, inglés, italiano). Del lenguaje vernáculo utiliza varios costarriqueñismos como "china", (por muchacha que cuida los niños) o "macho" (por norteamericano) y, excepcionalmente, el voseo después de justificar su osadía: "Y como nuestro objeto de escribir esta historia no es otro que dar a conocer nuestras peculiares costumbres y modos de ser usaremos de esta antigramatical manera de hablar, por más que ella sea nueva y desagradable para oídos extranjeros... Don Roque usaba el vos, provincialismo que equivale al tú..." (M.A.M., p.234-235)

El costumbrismo campea, entonces, en muchas de sus páginas. Desde breves descripciones de "costumbres" incluidas en textos netamente románticos: los paseos al volcán Irazú, las tertulias en los corredores, las diferentes formas de vestir de las mujeres según la clase a que pertenecen, las visitas de los novios... hasta cuadros completos donde los rasgos románticos o realistas están en desventaja. En los cuadros costumbristas, irónicos o más bien sarcásticos, se critica violentamente los vicios de la sociedad josefina; son excelentes los referidos a Simplicio Cucufate y su familia.

Cada uno de los personajes encarna un "tipo social" donde se conjugan, de forma caricaturesca, los vicios y defectos, casi siempre marcados por el nombre. El tío Silvestre Cocobola y Cedro Amargo, vive la amargura de su soltería; además de ignoran- te, es cretino y simplón. "Las hijas de doña Rogelia", olvidadas como la calle donde viven -Olvido, No.101-, representan tres grados de soltería; la de la esperanza de matrimonio "in extremis"; la que se consuela con una lora, un gato o un perro, y la que, ya sin esperanza, se refugia en la iglesia. Son pedantes, maliciosas y mal intencionadas al hablar: "aunque en cada familia se encuentran tipos semejantes o parecidos, es de esperarse, para la tranquilidad pública, que no todos tengan las abundantes dotes que adornan a las hijas de mi tía Rogelia" (M.A.M., p.410).

El primo Rufio Cascajal y Lodazales honra su nombre como abogado torpe y sinvergüenza: "un abogado... que no aboga; un jurisconsul to que no consulta..." (M.A.M., p.411). El cuñado, el Padre Estafas y Pamplinas: gordo e ignorante. El sobrino Cordelio: medio tonto, envidioso, cobarde, avaro y perezoso pero sobre todo imitador; el primo don Ramiro Salsipuedes y Canchalagua el que se dedica "a literato" porque no tiene otra cosa a qué dedicarse. La sobrina Juanita Cucufate, "el sumun de la coquetería", vive a la sombra de su tía Envidiana Verdinegro.

Los tres cuadros constituidos por Un abogado de fin de siglo, Un hombre honrado", y Los bienaventurados también explotan el humor y la ironía acre: el abogado don Cupertino Cantaparado, último vástago de la familia Bicicleta, pasa de la vida soltera de doctor no doctorado, bufete sin clientes y mediocridad cotidiana, a la vida en común con doña Venus Jamona. El hombre honrado presenta a dos matrimonios, el que aparenta y no es y el que no aparenta y es.... honrado. En La fiebre amarilla Simplicio Cucufate, describe a sus queridas mujeres y su deseo de aparentar lo que no tienen: Sinforosa, y siete preciosos retoños: Bailotina, Alborotina, Coquetina, Consertina, Descaradina, Lujosina, Coloretina y Corsetina, todas Cucufate, pero no tan sencillas ni tan comedidas, como su padre. No es difícil imaginar lo que resulta "un día nefasto" para el pobre Simplicio. En estos cuadros, y en otras páginas que aparecen intercaladas en diversos textos, Argüello Mora ataca con dureza las debilidades sociales, se burla de los convencionalismos e ironiza con múltiples temas "serios" (75).

\subsection{El determinismo y lo grotesco.}

El naturalismo, se evidencia, también en varios de sus textos. Refiriéndose a El martirio de una niña de cinco años en Matina, Fabián Dobles 
señala: "La historia se mueve en el ámbito del naturalismo más crudo... de sedimento final, deja solo repugnancia. Es el relato de bestialidad"'(76).

Algunos de los personajes de Argüello Mora sufren, - por distintas circunstancias- un proceso de degradación, es el caso de Fernando, el ciego de Torres. El autor cree en la fuerza del destino, en el "hado", y sus héroes -como en las novelas naturalistas- están muchas veces determinadas por la fatalidad: "Alli donde respiren juntos dos seres humanos de diferente sexo, habrá suficiente material para confeccionar desventuras e inverosímiles sorpresas suministradas por la fuerza de la fatalidad o... de la naturaleza" (M.A.M., p.291). "Eran tan inverosímiles e inesperados los golpes que nos asestó la fortuna que al fin llegaron las gentes a creer que nuestra empresa - la revuelta de 1860estaba irremediablemente condenada por el destino" (M.A.M., p.56).

Varias descripciones también corresponden al estilo naturalista, baste la que se refiere -en forma grotesca - al criado Zoilo: "A propósito de dientes, los de Zoilo son multicoiores, uno verdoso, dos amarillos, varios negruzcos, y el resto color de café tostado. Entre diente y diente, una argamasa blanca como la mezcla entre los ladrillos. Cuando ríe, aparece aquel mosaico ribeteado con los labios azules, y de los extremos de estos, manan dos cataratas de babas" (M.A.M., p.431).

\section{La Producción escrita: ¿Periodista, historiador, literato?}

\begin{abstract}
"Primeramente publicó sus obras en los periódicos, por entregas, y más tarde los recoge en libro. Por eso algunos lo tienen como periodista. Para nosotros fue un escritor".
\end{abstract}

\section{Francisco Núñez (77)}

\subsection{Polemista y crítico literario.}

Argüello Mora es un infatigable polemista; participa en discusiones de tipo político, jurídico, literario... La cuestión Mora y Aguilar no es más que una polémica de gran audacia y agresividad, con el abogado Fernando Streber.

Sobre todo, a finales de siglo, aparecen en EI Figaro, una serie de discusiones con Pío Víquez, Francisco Villafranca, Zenón Castro, "Persifal" y "Juan Soldado" (seudónimo) (78). En el 900,
Manuel Argüello critica, con otros, la obra de Joaquín García Monge, especialmente Las Hijas del campo (79).

\subsection{Los libros publicados.}

Resulta mucho más difícil la edición de libros que la participación regular en periódicos y revistas. Don Manuel publica su primer texto literario en Ia Imprenta La Paz, on 1860: Un drama en el presidio de San Lucas. Un hombre honrado. Las dos gemelas del Mojon. El resto, aparecen al finalizar el siglo: Páginas de Historia (1898, Imprenta El Fígaro); Costa Rica Pintoresca. Sus leyendas y tradiciones. Colección de novelas y cuentos, historias y paisajes (1899, Imprenta María v. de Lines); La bella herediana, El amor a un leproso (1900), Imprenta María V. de Lines). Historia de un crimen: El martirio de una niña de cinco años en Matina (1900, Imprenta María V. de Lines).

Estos, y otros textos publicados en Costa Rica Ilustrada (1887-1888) - con los seudónimos de Simplicio Cucufate y Sirio-, son recopilados en Obras literarias e históricas (Editorial Costa Rica, 1963).

\subsection{Fecundidad y anonimato.}

Don Manuel es un fecundo escritor: "Creo que no existe en Costa Rica escritor más fecundo que el señor Argüello Mora. En producción literaria me parece que no hay quien lo aventaje" escribe Eulogio Horta en el prólogo a Páginas de Historia (1898). En las palabras Al lector del mismo texto el autor se refiere a "más de seiscientas de mis publicaciones que en el último tercio de este siglo han visto. la luz..." En la cita anterior Argüello habla de lo publicado en el último tercio del siglo, y omite lo escrito con anterioridad. Buena parte de su obra queda inédita "me resolví a publicar algunos, muy pocos, artículos literarios, y muchos pasan o han pasado como "hijos de padres desconocidos"; "todo mi afán ha sido el ocultar mi nombre": Margarita Castro Rawson se refiere a Luisa, primer ensayo novelado que se conoce en el país, publicado en el número 8-9 de Crónica de Costa Rica. Aunque no está firmado, posee un estilo semejante al de Argüello, quien se anuncia como abogado en las páginas de la revista. Con escenario y motivos costarricenses e influida por el romanticismo parece ser obra de juventud del autor (80). Don Rafael Obregón Loría comenta 
sobre El testamento político del general Máximo Blanco (que aparece después de los acontecimientos de 1860) en él, Blanco se arrepiente de sus actos y los "ajusticiados" - en forma de espectros o conciencia- discuten y reprochan sus actos. EI lugar de la edición (EI Salvador) y la pluma hacen pensar en Don Manuel.

\subsection{El periodista.}

\subsubsection{Colaborador infatigable.}

Don Francisco María Núñez en Periódicos y periodistas lo ubica como colaborador en El Ensayo (1853), El travieso (1869), La Reforma (1877), El Boletín Electoral (1899) y la Revista El Figaro (1897-1900) (81). Justo Facio se refiere además, a El Correo de Ultramar; Castro Rawson a Crónica de Costa Rica, La República y El Heraldo y Elizabeth Portuguéz a La Revista... Según el mismo Justo Facio "colaboró en todos los periódicos literarios que salieron a la luz de la publicidad para desaparecer de repente... y enviaba a su vez, los frutos de su ingenio a renombradas revistas del exterior" (82).

Además de la fecundidad llama la atención -ya se ha dicho- la diversidad: "en la prensa periódica, paso a paso, día por día, tratando con original y serio juicio, ora puntos de historia nacional, o bien artículos de costumbres, resúmenes políticos, narraciones de viajes, cuestiones administrativas..." (82)

Su trabajo en los periódicos - considerados "no como una hoja lucrativa, sino como un agente educativo y cultural... y político" (84)-es de colaboración: columnas fijas, como Páginas de Historia, en El Figaro, o artículos, crónicas, descripciones sueltas, son diferentes motivaciones. Solo en una oportunidad dirige un semanario: "En 1878 funda el señor Argüello Mora, en compañía de don Bruno Carranza y del Dr. Rafael Orozco, un semanal que se llamó La Reforma y cuyo objetivo era encausar la política del General Guardia, Presidente de la República por las vías constitucionales. La prensa de antaño pesaba no poco en el movimiento político del país, sólo los hombres de autoridad y saber osaban en esos tiempos sentar plaza de periodistas" (85).

\subsubsection{La prensa oficial.}

En numerosas oportunidades, Argüello comenta el papel que juegan el periodismo y los periodistas, en la distorsión y manipulación de hechos reales (86). Critica el aparato de información y escritura en manos del grupo dominante -0 más bien oficial-, cuando él se encuentra en el campo opuesto: "Eso es lo que voy a contar, ese es el velo que voy a descorrer, pues en este asunto como en todos los demás relativos a nuestra historia política, las publicaciones oficiales, las gacetas $y$ periódicos oficiosos, solo cuentan lo que al círculo conviene que se sepa, siendo en la mayor parte de los casos todo lo contrario de la verdad" (M.A.M., p.32).

La prensa es, para él, un arma destructiva en manos hábiles... cuando los opositores a Mora deciden eliminarlo, empiezan una campaña a través de "la prensa y la palabra", tratan de cambiar la opinión pública para que acepte, sin problemas, el golpe de estado" (M.A.M., p.64), "se ha pretendido en publicaciones oficiales hacernos aparecer como invasores de la patria con fuerzas extranjeras" (M.A.M., p.67). La prensa es poderosa, su papel rápido y expansivo; apenas quince días después de la caída de Mora el pueblo norteamericano conoce la visión oficial: "iTal es la fuerza expansiva de esa dinamita del espíritu, la prensa, la diosa omnipotente que todo lo sabe y todo lo puede! " (M.A.M., p. 42).

\subsection{El historiador.}

\subsubsection{Memorias de protagonista o testigo apa- sionado.}

Manuel Argüello es "uno de los primeros en escribir sobre temas de actualidad...(87), "fue el cronista social de la época y además interesado en los hechos políticos e históricos" (88).

Argüello Mora, es un apasionado de la historia, que escribe muy ligada al periodismo y a la literatura. Para don Manuel hay tres versiones de los hechos históricos: la oficial, la del pueblo que solo "ve" y no conoce de pormenores y razones, y la suya personal que tratará de ser "objetiva y veraz" (M.A.M., p.33). Sus escritos no coinciden con la versión oficial: "Eso se comprende si se reflexiona el interés que tienen los diferentes grupos preponderantes en cada época, de paliar y a veces ocultar ciertos hechos que no les son favorables, o de recargar de tintas deslumbrantes $y$ exageradas algunos de los hechos o acontecimientos de que han sido autores" (M.A.M., p.20), y critica a los historiadores que se pliegan a esa versión de los hechos: "Y pensar que hay historiadores que, tomando por base los documentos 
oficiales describen y escriben la historia de hechos que no han existido y de fuerzas cuyo motor ignoraban" (M.A.M., p.92). Argüello aclara que sus escritos reflejan su visión de mundo, sus experiencias como testigo, protagonista o escucha de acontecimientos reales: "Consigo lo que he visto $y$ oído; describo y pinto las cosas y las personas como las he calificado y juzgado, con propio criterio, quizás algunas veces erróneo pero nunca apasionado ni conscientemente falso" (M.A.M., p.19-20), se trata de "memorias o autobiografía": "más que relato o bosquejo histórico mis escritos son pura y simplemente un reflejo de mi memoria" (M.A.M., p.20). "Treinta y cinco años hace que estos acontecimientos se verificaron $y$ aún hoy siento en el corazón algo de la suave y poética impresión que me produjo la llegada a Santa Tecla..." (M.A.M., p.50). Según sus palabras escribe para aquellos que "desean conocer algunos puntos oscuros de la historia" y a petición de su hijo y algunos amigos... (M.A.M., p.19).

\subsubsection{La "verdad".}

Don Manuel desprecia la escritura que talsea la verdad deliberadamente: "y en un país como éste donde los que conocen la verdad no quieren certificarla, ni aún siquiera consignarla por escrito en memorias, en cartas o de cualquier otro modo, ya sea por temor a herir algunas susceptibilidades, o por pereza o culpable indiferencia, es verdad que quedaría sepultada para siempre en las brumas del olvido" (M.A.M., p.33), o la oculta:"Los numerosos impresos que en aquella época vieron la luz poco nos enseñan y no merecen crédito alguno porque, de ambos ĺados la pasión política velaba u ocultaba la verdad" (M.A.M., p24).

Decir la verdad es una de sus obsesiones, aún cuando tenga que pagar por su osadía:"No quiero disimularlo pues en materias históricas prefiero escribir mi vergüenza antes que ocultar el menor detalle que ponga en duda mi sinceridad" (M.A.M., p.43); muestra su desilusión personal cuando Mora no se vende al presidente de Estados Unidos (M.A.M., p.47-48); su miedo cuando se despoja de las ropas de su grupo para poder huir, en 1860 (M.A.M., p.69); y su dureza cuando considera que deben fusilar a Aranabia en el acto (M.A.M., p.58). Claro que su torpeza personal, le sirve para exaltar otras figuras, sobre todo la de don Juan Rafael.

4.5.3 La epopeya de 1860: héroes, pueblo y enemigos.

Sus páginas de historia constituyen una verda- dera epopeya, un canto a los héroes del 56 y, a la par, un canto al pueblo: "lleva la mano al detalle, al moroso acontecer de la vida de los héroes sin nombre como en la sobre la Revolución Mexicana del historiador Fernández Güell" (89). La lucha no la hacen Juan Rafael, Cañas, José Joaquín y Manuel, la batalla la libran los costarricenses que llegan a defender a su líder; la batalla es del pueblo, un pueblo armado desde la revuel ta contra los filibusteros en el 56 (M.A.M., p.56). Manuel Argüello llena páginas históricas con las anécdotas de los soldados, muchos de ellos sin nombre ni rango, aquellos que defienden la Patria, en 1856, o en el paso de la Angostura... la Lorenza, los Joricas (padre e hijo en bandos contrarios), Salvador Guevara, Juan María Murillo, Antonio Argüello, Espíritu Santo Solera, Torcuato Monge, Toribio Artavia o Clodomiro Barquero, Blas Alpízar, Ambrosio Flores y sus cuatro hijos...

El autor pretende ser justo: admira al "enemigo" valiente, honesto; el pertenecer al otro bando no implica una actitud hostil de su parte. Esto es en cierto sentido comprensible, al ser los dirigentes de los dos grupos en conflicto, una misma clase. Al joven Argüello lo salvan de la muerte sus "enemigos-amigos". Reconoce las virtudes, incluso de los líderes que más adversa política y personalmente: Vicente Aguilar (M.A.M., p.86), Máximo Blanco (M.A.M.; p.75), José Ma. y Francisco Montealegre (M.A.M., pp.85 y 73).

Los acontecimientos más importantes están matizados de anécdotas, de detalles. La descripción realista se combina con el sentimiento, la opinión, el consejo y la ironía.

\subsubsection{Historia novelada.}

Para José Marín Cañas el gran acierto de Argüello es el no haber sido "un historiador objetivo...": "si fuera imparcial, crítico, viviseccionador de los hechos, juzgados todos ellos a través de una serena y objetiva visión, es posible que la obra resultara históricamente erudita e irreversiblemente pesada. Lo que le mete un fuego especial, totalmente "sui géneris" es la pasión, la parcialidad de sus opiniones, el furor que injerta tanto en los hechos como en las circunstancias... Todo lo que escribe, es historia novelada $-\mathrm{He}$ aquí..., la gran importancia del autor" (90).

\subsection{El escritor literario.}

\subsubsection{La conciencia de "literato".}

Argüello Mora tiene plena conciencia de que, 
parte de su obra es literaria. En el prólogo de Páginas de Historia expresa -con "falsa modestia"- su temor de que el público ilustrado pueda confundir su intención con "una vana pretensión al título de autoridad de una obra literaria" y luego afirma que, aunque escribe desde tiempo atrás, solo en los últimos años se anima a publicar algunos "artículos literarios".

Se conduele de que "desgraciadamente no es con la literatura ni con la reputación de valor que se puede vivir en Costa Rica. Está averiguado que una libra de café de tercera clase tiene un valor efectivo mucho mayor que un libro de sonetos..." (M.A.M., p.421); y critica a quien sin tener verdadera vocación, se convierte en "literato-vividor social": "Recuerda cuántas veces has tenido que contribuir... a la existencia artificial de mi literato primo, el más inofensivo sujeto quizás de todos tus amigos" (M.A.M., p.423).

Entre broma y serio, Don Manuel define al literato-polifacético de la época: "Los literatos hacemos versos, escribimos novelas, cuentos, fábulas, máximas y pronunciamos discursos floridos, didácticos, épicos e históricos" (M.A.M., p.424) y se refiere al que no compra nunca libros pero lee $y$ tiene biblioteca particular: "Lee los libros que le prestan, de los cuales unos devuelve y otros adquiere por prescripción" (M.A.M., p.406).

Para él, el escritor tiene el privilegio de "adivinar lo presente y lo futuro" (M.A.M., p.282), pero además, debe aprender el oficio: "No lector de mi vida. Se nace poeta y se aprende a hacer versos" (M.A.M., p.426).

\subsubsection{Fantasía y realidad: lo verosímil y lo verdadero.}

Para la mayoría de los críticos, entre ellos Valdeperas, en Argüello Mora "no se ha establecido aún la divisoria de procedimientos entre la narración histórica y el relato literario, ya que en su obra los momentos novelados aparecen solo como pretextos para que el autor pueda referirse a los hechos históricos vividos por él" (91).

Es interesante constatar que el autor trata de hacer conciencia en el lector, de que hechos verídicos parecen imaginarios y a la inversa: "Inverosímil, dirá la una, absurdo, dirá la otra; y todas a un tiempo invenciones de novelistas $y$ autores dramáticos" (M.A.M., p.310). Vamos lector incrédulo no hay que burlarse de la inverosimilitud de mi narración. Recuerda cuántas veces has tenido que contribuir..." (M.A.M., p.423). Relata- ré el principal suceso, el más inverosímil y el que más contribuyó al fracaso" (M.A.M., p.56). "Puede ser que el cariño al terruño me engañe; puede ser que el autor de esta historia-cuento, sea un irremediable optimista" (M.A.M., p.365)... "se realizó este idilio tan íntimamente ligado con el drama más sangriento de nuestra historia" (M.A.M., p.305). "La casa No.109 de la calle del comercio presentaba, el día que comienza esta verídica historia..." (M.A.M., p. 213). Historia y fantasía, realidad e imaginación, verdad y verosimilitud...entrelazadas.

\subsubsection{Mecanismos de realidad o verosimilitud.}

\subsubsection{Datos y trucos.}

En todos los textos de Argüello Mora, aún los imaginarios, se introducen una serie de mecanismos de realidad o verosimilitud: fechas, lugares geográficos, nombres de instituciones, iglesias, hoteles, carreteras, haciendas... Los nombres de personajes reales se mezclan con los ficticios; se especifican direcciones; se incluyen cartas, documentos, letras de canciones...

Se utilizan trucos diversos como el del narrador que relata lo que le contaron: "Tal es la triste relación que me dictó Lucía en el Hospital Nacional de locos el día de la visita pública del establecimiento" (M.A.M., p.209), "Entonces fue que se me ocurrió publicar la presente historia, valiéndome del señor Sirio, quien lo escribió bajo mi dictado" (M.A.M., p.139); el mecanismo del sueño: "En efecto... todo era un sueño producido por el hastchiz" (M.A.M., p.356); la reproducción de un texto escrito: "Lo que siguió, lo copiamos de un libro en que Arturo consignó los sucesos de aquella noche inolvidable" (M.A.M., p.351); el intercambio epistolar (Misterio), o la inclusión de cartas $u$ otros documentos: lo demás lo sabrá si lee la correspondencia que a la letra copiamos" (M.A.M., p.225).

\subsubsection{Apelación al lector... o lectora.}

Continuamente se apela, de manera directa al lector, y se le hace participar de la trama, ya sea enviándole a verificar la historia: "pues las ofrezco a mis lectores a precio corriente se toman el trabajo de dirigirse a mi habitación, que es la casa No.339 de la calle Santa María..." (M.A.M., p.140) "y todo lector curioso puede verla en la Iglesia de 
la Merced" (M.A.M., p.344); identificándolo con la trama, los personajes o el narrador: "Puede figurarse el lector io que yo sentiría” (M.A.M., p.47). "El lector pensará como yo..." (M.A.M., p.233).

Algunas veces, el tipo de argumento y el estilo folletinesco e hiperbólico lo lleva a identificar con el texto, específicamente a la mujer: "Ahora bien, querida lectora: ¿quieres saber cuál era la desconocida ninfa que había hipnotizado a Julio...? " "Sí, señoras..." (M.A.M., p.171). "Pero donde el asombro del sexo bellísimo va a alcanzar descomunal proporción..." (M.A.M., p.310), "Lectora, si eres bonita o graciosa...". (M.A.M., p.430).

\subsubsection{Lo moral y lo didáctico:}

Argüello es moralizante. Sus "máximas" ocupan un espacio significativo: "iTanta es la fuerza de lo humano y de lo bello, que engrandece $y$ bonifica a los pequeños y a los malvados!" (M.A.M., p.40) “ iPobre humanidad si así lo fuera. La idea misma de un placer interno, amargaría ese placer!" (M.A.M., p.289). La opinión ética aparece como juzgamiento o valoración de actos y personajes.

Los textos son didácticos; el narrador aconseja, sugiere, recomienda, ordena: "Figúrese el lector una mujer..." (M.A.M., p.298), "cuidado pues, lector de mi alma, con las pastillas hastchiz, y procure sacar de esta novelita la moralidad que en ella pudiera seros útil" (M.A.M., p.357); "Llevad una buena provisión de salud, de juventud y de amor a lo desconocido y lo demás viene solo" (M.A.M., p.452).

El epílogo o la moraleja sirve no solo para dejar una enseñanza, sino como mecanismo de realidad.

\subsubsection{La programación como discurso.}

En los textos se guía al lector: hay retrocesos en la narración, se adelantan acontecimientos, se resumen los hechos pasados, se enfatiza en lo importante, se hace referencia a otros textos - del mismo Argüello- donde se completa el tema o se amplía: "Recordará el lector..." (M.A.M., p.304). "Plugiera el Cielo que no se le hubiera ocurrido semejante cosa, como el lector verá más adelante" (M.A.M., p.316). "Así concluyó..." (M.A.M., p. 391 y 396). "Resumiendo los acontecimientos encontramos" (M.A.M., p.345). "Y que contaremos al lector en el siguiente capítulo" (M.A.M., p.225). "Veremos primero lo que en Costa Rica se hizo para esperarnos, y luego contaremos lo que nosotros hicimos" (M.A.M., p.54). "Una ligera relación de este atentado nos servirá de punto de partida para que el lector comprenda el encadenamiento que tienen entre sí las diferentes publicaciones hechas con el título de Páginas de historia, Apuntes para la historia, Secretos de la Historia, etc., etc..." (M.A.M., p.24). "En mi artículo Secretos de la Historia relato lo más interesante de nuestro paso por los Estados Unidos" (M.A.M., p.29).

Como se aprecia en las dos últimas citas, hay una clara conciencia de que cada uno de los artículos forma parte de un texto unitario.

Otras marcas de la programación como discurso -como comunicación - son también reiterativas: divide los textos en capítulos; incluye epílogos; utiliza subtítulos; marca el "fin del episodio"; dedica los artículos a amigos o parientes: Clemencia de Vars Argüello, Cleto González Víquez, Celina Mata, Adela Cañas de Beeche.

\subsubsection{Autor-seudónimo/narrador-actor.}

El juego que se establece entre el llamado autor-narrador-actor Ilamado Manuel Argüello Mora, también contribuye a hacer verosímil el texto. El autor se incluye de forma autobiográfica - primera persona del singular o plural-como actor de su propio texto. Otras veces, introduce al personaje Argüello Mora, desde la perspectiva externa de un narrador que no es él mismo -el narrador habla de Argüello Mora-.

Este mismo juego lo realiza a través del no-yo del autor, figura intermedia entre éste $y$ un narrador externo que es el seudónimo: Simplicio Cucufate o Sirio firman como narradores o actúan como personajes principales, secundarios o referenciales.

Este juego autor/personaje, autor/seudónimo/narrador, por su misma combinación y variedad representa una ruptura. Existe una lucha constante entre èl ócultamıento y la mostración del "dueño" de la palabra y de la escritura. Se da una gradación entre lo autobiográfico, el testigo como actor secundario, el personaje real-ficticio que representa el seudónimo-persona, y el narrador impersonal que a veces aparece como omniciente. El seudónimo no es un simple narrador, trasciende ese estatus para convertirse en personaje ficticio de la propia narración: Simplicio Cucufate o Sirio son y no son Argüello Mora. Sirio aparece en el Huerfanilo de Jericó al lado del dueño de Nueva 
Corinto, Manuel Argüello Mora. Simplicio Cucufate logra aún una mayor autonomía. Simplicio -ya se ha dicho- es semillero de una gran familia de tipos caricaturescos sobre la que, enconadamente, ironiza él mismo, como padre, tío primo, sobrino... narrador y personaje.

A veces el texto es autobiográfico, pero es un personaje el que asume su propia historia, es el caso de Carlos el enamorado de Paulina, la Sonámbula del Pirro o El Huerfanillo de Jericó, el pícaro rural que relata sus aventuras. La focalización en el niño de diez años se mantiene a través de la narración, lo que le imprime una buena dosis de realismo.

El diálogo, el monólogo, el sueño como representación mimética de la palabra también contribuye a la verosimilitud.

\subsubsection{La función expresiva y los personajes.}

La función afectiva del narrador está fuertemente representada; las descripciones de los personajes, de los hechos que resaltan determinadas virtudes o defectos; las exclamaciones; las preguntas; las sugerencias, pero sobre todo la adjetivación, a veces excesiva, matiza los textos.

La escala de valores de don Manuel se evidencia, a cada paso, de forma directa o a través de la ironía: admira al estudioso, al inteligente; desprecia la estupidez y la torpeza. Ama la sencillez, lo pequeño y lo grande, los pueblos y los héroes, la justicia y por encima de todo, su "verdad". No admite la hipocresía, las malas lenguas ni la vanidad. Defiende el matrimonio - los solteros son objeto de su sarcasmo-. Rechaza la superficialidad y promueve el conocimiento. Ama el azar, el suspenso, lo que va más allá de lo racional o verosímil, aunque termine ajustándose a ello.

Los personajes sufren castigos por sus faltas $y$, aunque las acciones positivas no siempre son premiadas, se pretende que, -excepto en casos irremediables como lo son la locura y la muerte-, el ser humano encuentra alguna compensación o equilibrio.

Los personajes, con la excepción de los que configura como tipos, caricaturas de los vicios y estupidez de una sociedad, no son maniqueos. Si bien es cierto que la afectividad del narrador los marca como más positivos o más negativos y los carga de virtudes o defectos, fealdad o belleza, presentan rasgos o actúan en determinado momento de una forma que reivindicar sus errores o muestra que pueden equivocarse. Incluso los personajes reales -quizás con la sola excepción de Juan
Rafael Mora o de individuos que pasan como ráfagas sin vivencia - son objeto de ironía: sirva de ejemplo la figura "adorada y adorable" del General Cañas: valiente, hermoso, viril pero mujeriego, tartamudo y con dientes postizos. Los personajes ficticios presentan una mayor o menor evolución sicológica. Ciertamente, en algunos momentos, el cambio parece radical y de relación simbólica (de bueno a malo o de malo a bueno), pero, en otros casos, el cambio no es absoluto y resulta ruptura, muestra rasgos sígnicos (92). La novela rosa o folletinesca de la que mucho tienen algunos textos de Argüello, es mucho más rígida.

La figura del niño y el joven es relevante dentro de la obra de don Manuel: las aventuras de Pedrito de Jericó; la figurilla de Julieta víctima de la tuberculosis en el sueño de Arturo, su insatisfecho padre; la chiquilla que recoge el billete de banco, las víćimas del internado del Padre Paúl; el aún pequeño Juan Valera que queda huérfano por el cólera y empieza a vagar en Londres sin apoyo, ni dinero; las familias con niños donde trabaja el huerfanillo de Jericó...

La mujer, también ocupa un lugar fundamental en la obra de Argüello: las mujeres de "carne y hueso" que apoyan a los moristas; las que juegan el papel de esposa, madre, hermana, amiga..., las jovencitas de buenas familias cultas, "viajadas", y las orilleras con perfume de campo y trajes frescos; las protagonistas de dramas truculentos, fuertes las más y siempre honestas; las heroínas como Elisa del Mar, la Lorenza o Florencia. Las mujeres tipos con su superficialidad, coquetería, vanidad, o malicia... Muchas de las mujeres dan nombre a sus cuadros Elisa del Mar, Las gemelas del Mojón, La Sonámbula del Pirro, Margarita, La bella herediana, La Loca de la Avenida Central, pero en todos la mujer cumple un papel fundamental. Sus mujeres aman, sufren y piensan.

\subsubsection{Las diferencias de clase, raza y naciona- lidad.}

Las diferencias de clase aparecen muy claras en los distintos textos. En las Páginas de Historia -ya se afirmó- el pueblo juega un rol importante, lo mismo que en las tramas novelescas (campesinos, artesanos, criados). Manuel Argüello es consciente de las distancias económicas y aunque no es la tónica de sus relatos, se refiere a la pobreza, y la marginalidad. Pedrito, el huérfano de Jericó se retrata como un niño "pobre": "Yo tenía entonces diez años de edad, un cuerpo pequeño y raquítico" (M.A.M., p.121). En el caso anterior, se trata 
de un "mal social", en otros, como el de Fernando, "el ciego de Torres", la miseria es producto de la escogencia personal.

Las diferencias raciales se marcan también. Aunque se refiere ocasionalmente al indio $y$ al oriental, es el negro quien Ilama su atención. La negra Paula de El Martirio de una niña de cinco años en Matina, y el Negro Phelps, el primer amo de El Huerfanillo de Jericó son personajes centrales. En El Huerfanillo de Jericó se refiere, además, a los negros jamaicanos como grupo trabajador. Su negro posee algo folklórico, de extraño, de diferente. Una visión que corresponde, desde luego, a la época: "constituye un testimonio ideológico que denota históricamente la actitud mental para con el negro de los sectores dominantes de la época" (93). La visión de la Paula es absolutamente racista y maniquea, representa el mal, frente a la familia buena y blanca de Elisa -la niña $-y$ el perfecto empresario norteamericano. EI negro Phelps alcanza - a pesar de su comportamiento (enseña a robar a Pedrito) - una dimensión humana; la relación es afectiva y el problema personal más que social -aún cuando se haga referencia al trabajo y las condiciones climáticas negativas de la zona bananera-. A fines del siglo XIX y principios del XX, varios costarricenses incluyen al negro en la literatura, con una visión semejante, a pesar de sus diferencias; es el caso de El ahorcado de Fernández Guardia (94), Leña de Teño, con su típico Mr. Wiskey (95) y Los trocitos de carbón y Los negritos de Carlos Gagini, con finales emotivos donde el blanco racista acepta y.se amiga con los "bondadosísimos" negritos (96).

Los personajes de nacionalidad extranjera -reales o ficticios-contribuyen con las tramas novelescas: la francesa Mlle. Roqueval, el polaco Rakosky y su criado Puck, Mr. Mme. Robineau o Ana Worzinsky para solo nombrar algunos de Misterio. El predominio de personajes costarricenses es, sin embargo, absoluto.

Históricos o ficticios casi todos los textos de Argüello Mora tienen ubicación espacial (y temporal) como un mecanismo de verosimilitud: tres son las zonas del país privilegiadas: San José, Heredia y la Zona Atlántica. Excepcionalmente se recurre a otros lugares como Cartago.

Los escenarios se ubican en medio de la naturaleza, pero sobre todo en las ciudades a las que dedica breves y excelentes descripciones. Si se sale de Costa Rica es por un viaje de estudios, de placer o por circunstancias especiales, nunca sus cuadros se enmarcan en un paisaje exótico: el ambiente es costarricense, muchas de sus costumbres y vicios también, y sus personajes, de la "pura cepa".

Argüello describe, de diversas formas, personajes y ambiente; si se toma el caso de la naturaleza se puede constatar esta variedad. En unos casos, existe una total identificación entre el hombre y su medio: Pedrito de Jericó entierra a sus padres en medio de una noche oscura y tormentosa, la lucha entre un cabrito y el tigre se asemeja a la suya con el negro Phelps (M.A.M., p.121 y 129). La noche se cierne sobre Carlos cuando éste sufre y se angustia por Paulina (M.A.M., p.199). Otras veces, el paisaje es indiferente: Manuel Argüello va a ser fusilado, y mira por la ventanilla el claro y paradisíaco ambiente (M.A.M., p.82). Lo romántico y lo realista.

El paisaje aparece identificado con las emociones, como simple descripción estética pero también como mostración de zonas de trabajo. El Huerfanillo de Jericó es el texto más rico en variedad: Una naturaleza inhóspita y malsana, llena de humedad y de miasmas. La selva atlántica exuberante y hermosa. Las fincas bananeras con sus procesos de corta y cuidados agrícolas. Las montañas donde los huleros nicas explotan el producto. La barbarie y la civilización, el campo y la ciudad. La selva, las haciendas, las carreteras y la ciudad.

4.6.9 La crítica económico-social y lo sicológico.

La crítica ideológica se vislumbra en algunos párrafos de la obra de Argüello. Por ejemplo, en El Huerfanillo de Jericó y en La Historia de un billete de banco se plantea ya la explotación de los extranjeros: "Recién hechos los desmontes para plantar los bananos que tanto beneficio habían de producir a dos o tres personas y tanta pérdida de dinero, de salud y de vida para los costarricenses..." (M.A.M., p.122). "En este trayecto me fastidió el olor a bananos podridos, que según supe después eran millares los racimos que Mr. Keith rechazaba, con razón o sin ella, a los pobres agricultores, que con tanto costo los habían cortado y conducido hasta allí" (M.A.M., p.385).

Si la literatura realista-social se encuentra en embrión en la obra de Argüello Mora, otro tanto ocurre con la llamada "literatura sicológica o de introspección" donde se explotan los caminos de la inconsciencia o semi-inconsciencia: el pensamiento febril, el sueño, el desvarío, la hipnosis, el 
trance...: la locura y la ensoñación de la Delfina de Misterio. La Loca de la Avenida Central, La Llorona, o Elisa una de Las dos gemelas del Mojón...; el sueño angustioso-fantástico de Arturo en La poza de la Sirena; las pesadillas de Argüello Mora en la cárcel cuando está Condenado a Muerte; el sonambulismo de la bella del Pirro; los espectros de la muerte en El testamento político del General Máximo Blanco, el tartamudo del General Cañas...

Las dos vertientes más importantes de la novelística contemporánea "lo social y lo psicológico" (97) están entonces, en germen, en la narrativa de Argüello.

\subsubsection{La comparación y la ironía.}

Hay, con pocas excepciones, un sentido irónico general en los textos de Argüello Mora; en los humorísticos, los históricos y aún en los trágicos. Don Manuel golpea fuertemente con su sarcasmo y provoca la reflexión. No toda la ironía es risueña -a veces se presenta grotesca, otras cruel y sarcástica, pero siempre con un dejo de humor.

Argüello compara: la naturaleza y el hombre, Costa Rica y el extranjero, la clase alta y la clase popular, lo negativo y lo positivo, el pasado y el presente... Compara personajes, acciones, paisajes, objetos... establece diferencias... y semejanzas. La ironía y la comparación son, entonces, ejes de su escritura (98).

\section{Síntesis}

La producción escrita de Manuel Argüello Mora hace evidente la sociedad en que le toca vivir, las posibilidades que le ofrece el medio y las continuas contradicciones en que se debate el país -en la segunda mitad del siglo pasado-: sociedad patriar$\mathrm{cal} /$ sociedad liberal, interés por la lengua/interés por la lectura, estudios académicos/ autodidactismo, imitación/trabajos personales de una cierta originalidad, realidad/imaginación...

Don Manuel, más que un precursor, se puede considerar el iniciador de la literatura costarricense: su obra, con todas sus variaciones (páginas históricas, crónicas, cuadros de costumbres, ensayos periodísticos, cuentos, leyendas, novelas, discursos, impresiones de viajes...) se puede ordenar en tres estadios (cada uno con sus contradicciones internas como texto unitario), por su intencionalidad:
- Textos históricos e impresiones de viajes, donde lo más importante es la narración de hechos del pasado -vividos como testigo o actor-, y la descripción "objetiva" de lo que conoce en sus viajes. Trata de reflejar la "verdad" y de mostrar la "realidad".

- Textos histórico-literarios: en ellos mezcla acontecimientos históricos con tramas imaginarias. Es el caso de las llamadas por él "novelas históricas" y de algunos cuentos o crónicas. En ocasiones amalgama historia y fantasía, en otras, construye narraciones paralelas que se unen en determinado momento.

- Textos literario-periodísticos: aquí se incluyen leyendas, ensayos, cuadros de costumbres, crónicas de actualidad, críticas, polémicas... de temática muy variada, y una gran dosis de imaginación y realismo.

La clasificación anterior se establece por predominios - gradación-, puesto que, aún en los textos más imaginativos y románticos se encuentran gran cantidad de mecanismos de verosimilitud (cartas, fechas, lugares, personas, direcciones...) y, en las páginas históricas, "verdaderas y objetivas", la subjetividad se impone a cada momento y, descripciones de acontecimientos, personajes o paisajes resultan novelados, verdaderos fragmentos literarios.

Manuel Argüello es uno de los prototipos del siglo XIX: culto, de clase alta, con posibilidades económicas y académicas: ideólogo de la clase dominante, filósofo, abogado, hombre público, lector, estudioso de la lengua, educador, comerciante, bibliotecario, finquero, dueño de una librería, periodista... que incursiona en el trabajo de la escritura con exuberancia y timidez.

Sus textos son ambivalentes y contradictorios, como su época. Introduce temas, estilos, condiciones nuevas, y se agarra de la tradición. Da rienda suelta a su ingenio $y$, de pronto, vuelve sus ojos al lector y lo conduce. Una realidad de cambio y consolidación de la nacionalidad; un momento de imitación y de ruptura.

En sus escritos se percibe la huella de textos universales ya superados (románticos, costumbristas, picarescos...) y la irrupción de los contemporáneos: realismo y naturalismo. Se encuentran huellas de lo europeo y lo norteamericano (allá, exótico, diferente) y ambientes, personajes, costumbres, tradiciones y ciertos rasgos de lenguaje costarricense.

En la producción de Argüello se encuentran los gérmenes de múltiples temáticas y orientaciones 
que se van a desarrollar, tiempo después, en la literatura del país: el interés por lo sicológico, por la crítica contra la explotación extranjera, la crítica social y política, el negro como motivo literario, la naturaleza del Atlántico...

Este artículo es producto del análisis cuidadoso de la época, el hombre y los textos escritos, y como tal es intertextualidad. Un trabajo de elaboración donde participan todos los textos que se han ocupado del tema, los de la historia y de la cultura que le dan origen, y los personales de don Manuel.

Lo polifacético, amplio y valioso del material, posibilita numerosas investigaciones posteriores: aquí, con el ánimo de brindar un cuadro más o menos unitario, muchas de las observaciones quedan como problemas pendientes.

Una época de apertura, rica, múltiple y un digno representante de la tradición. Quizás por esto, la crítica se queda a menudo en lo que no es y piensa en lo que pudo haber sido... don Manuel.

Contradicción, ambivalencia, imitación, intento de ruptura, y embrión de la literatura posterior.

\section{REFERENCIAS BIBLIOGRAFICAS}

(1) Manuel Argüello Mora. Obras Literarias e Históricas. San José: Editorial Costa Rica, 1967; p.426. Para comodidad del lector, se utiliza esta recopilación y se incluyen, al lado de los textos del autor, las siglas M.A.M. y el número de página. La antología presenta varios errores de transcripción: cambios tipográficos, cambios semánticos. Uno de los errores, señalado por el profesor don Rafael Obregón Loría, sirve de ejemplo: en Elisa del Mar en lugar de "el Ballardo" centroamericano, ballardo por el caballeroso militar francés y centroamericano por José María Cañas, se copia "el gallardo centroamericano" (p.143).

(2) Eduardo Galeano. "Diez errores o mentiras frecuentes sobre la literatura y cultura en América Latina". En: Nueva Sociedad. México, setiembre-diciembre $1981 ;$ pp. $65-78$.

(3) Abelardo Bonilla V. Historia de la literatura costarricense. San José: Editorial Costa Rica, segunda edición, 1967.

(4) Margarita Castro Rawson. El costumbrismo en Costa Rica. San José: Imprenta Lehman, 1971.

(5) Manuel Picado Gómez. Literatura. Ideología. Crítica. Notas para una historia de la literatura costarricense. San José: Editorial Costa Rica; 1983.

(6) Rogelio Sotela. Escritores de Costa Rica. San José: Imprenta Lehmann, 1942; p.22-23.

(7) Idem.
(8) Seymour Menton. El cuento Costarricense. México: Editorial de Andrea, 1964; p.9.

(9) Alfonso Chase. La narrativa contemporánea de Costa Rica. Costa Rica: Publicaciones del Ministerio de Cultura, Juventud y Deportes, 1975; Estudio Preliminar.

(10) A. Bonilla V. Op. Cit., p.112.

(11) Manuel Argüello Mora. La Trinchera y otras páginas históricas. San José: Editorial Costa Rica, 1974. Introducción de José Marín Cañas. Además Marín Cañas publica dos artículos en La Nación: "El próximo libro: La trinchera" (17 octubre, 1974) y "Incursión en la literatura patria: Manuel Argüello Mora" (29 diciembre, 1974).

(12) Eulogio Horta. "Prólogo". En: Manuel Argüello M. Páginas de Historia. San José: Imprenta El Fígaro, 1898/Blanca Milanés. "Don Manuel Argüello Mora". En: Obras literarias e históricas. Op. cit. Contraportada/Justo Facio. "Don Manuel Argüello Mora". En: Páginas llustradas. San José, Año III, No.102, 8 de julio 1906/Aquileo Echeverría. "Don Manuel ArgüeIlo Mora". En: Páginas Ilustradas. San José, Año III, No.102, 8 de julio 1906/Alfonso Chase. "La Trinchera y otras páginas históricas". En: Excelsior (Costa Rica), 1 noviembre 1975; p.4. Rogelio Sotela. "Don Manuel Argüello Mora". En: Revista de Archivos Nacionales. Costa Rica, Año V, No.11-12, 1941; p.613/Luis Ferrero. Elisa del Mar. En: La República, 8 de marzo 1953; p. 1 y 8/Gerardo César Hurtado "El libro de hoy: La Trinchera". En: Universidad (Semanario de la Universidad de Costa Rica), 1 setiembre 1975/Ernesto Castegnaro. "Manuel Argüello Mora". En: La Nación,, 17 setiembre 1975/... "Costarricenses ilustres". En: La Nación, 24 de setiembre de $1975 \ldots$

(13) En varias ocasiones, la reproducción se hace sin citar la fuente.

(14) Manuel Picado Gómez. "La literatura: entre el diálogo y la metalengua". En: Káñina (Revista de Artes y Letras de la Universidad de Costa Rica). Vol.III, No.1, enero-julio 1983; p.89.

(15) A. Chase. "La trichera..." Art. cit.

(16) Jorge Valdeperas. Para una nueva interpretación de la literatura costarricense. San José: Editorial Costa Rica, 1975; p.30.

(17) Alvaro Quesada S. "Dos cuentos de Fernández Guardia: "El estreno" y "La política". En: Revista de Filología y Lingüistica de la Universidad de Costa Rica. Vol.IX, No.1 y 2, marzo 1983; p.143.

(18) En el semanario Universidad del 12 de enero de 1979, se encuentra un buen ejemplo de la crítica absurda...

(19) Manuel Picado G. se refiere a la lengua de la crítica y 
señala tres oposiciones fundamentales: lenguaje referencial/no referencial, presencia/, ausencia del autor, naturalidad/artificiosidad del texto. Con poquísimas variantes, estas dicotomías nutren las críticas de Argüello Mora. En: Literatura. Ideología. Crítica; p.41.

(20) J. Valdeperas. Op. cit.

(21) M.A.M. "Ligero esbozo de la vida de don Juan Rafael Mora" Op. cit., p.67. Con una mezcla de ironía, sentido trágico de la vida e ingenuidad, don Manuel señala lo efímero de la existencia humana y da un sentido histórico al hombre. Durante mucho tiempo, un agudo dolor en la boca del estómago, lo obligó a ingerir pequeñas dosis de morfina y le dificultó aún más la existencia.

(22) M. Castro Rawson. Op. cit.; p.67.

(23) J. Valdeperas. Op. cit.; p.21.

(24) Para la interpretación del siglo XIX como un siglo de transición y otros aspectos, las conversaciones y la tesis de doctorado (Continuidady cambio en la historia agraria de Costa Rica -1821-1880-) de Yamileth González García, resultan fundamentales.

(25) Louis Althusser. "Idéologie et Appareils idéologiques de I'Etat”. En: La Pensée, No.151; 1970. Este estudio permite la comprensión del juego represivo/persuasivo que se establece en los diferentes gobiernos. En este sentido confróntese "Censura -autocensura y juego circular de información" de María Pérez Y. de próxima aparición en la Revista de Ciencias Sociales de la Universidad de Costa Rica.

(26) A. Bonilla. V. Op. cit, p.31-32.

(27) José Luis Vega C. ha publicado numerosos artículos y libros sobre el período.

(28) M. Castro Rawson. Op. cit., p.318.

(29) Este texto aparece publicado en el libro de Quince Duncan: El neyro en la literatura costarricense, con un prólogo de Fabián Dobles (Editorial Costa Rica, 1975). Originalmente, aparece en forma de folleto con el título Historia de un crimen, en la Imprenta María v. de Lines, en 1900.

(30) A. Bonilla V. op. cit.; p.33.

(31) A. Chase. "La trinchera..." Art. cit.

(32) Rodrigo Facio. "Prólogo o estudio preliminar". En: Rafael Obregón Loría. Los rectores de la Universidad de Santo Tomás. San José, Costa Rica: Editorial Universitaria, 1955; pp.20-21.

(33) Don Manuel descuida las fechas; por ejemplo, afirma partir en 1854 a su primer colegio (20 años) y luego señala que tiene nueve años. Además en 1854 ya se había graduado en la Universidad de Santo Tomás.
(34) Francisco María Núñez. Periódicos y periodistas. San José: Editorial Costa Rica, 1980; p.49.

(35) La figura de Juan Rafael Mora es controversial, algunos lo idealizan como un héroe sin mancha y con gloria, otros lo consideran un oportunista... todo depende de la perspectiva y el "bando" desde donde se escriba la historia. Por ejemplo, don Carlos Meléndez, quien anota los errores históricos de don Manuel en Obras Literarias e Históricas, da una visión negativa del expresidente Mora, en el libro sobre su oponente don José María Montealegre.

(36) Manuel Argüello representa a su tío como abogado, y Fernando Streber a don Vicente Aguilar. De esa época se conservan numerosos y rudos alegatos de ambas partes, que fueron publicados posteriormente por la Revista de los Archivos Nacionales. En las memorias de don Manuel Echeverría Aguilar, -nieto de don Vicente - se atribuye la muerte de Aguilar al último escrito, virulento $y$ acusador, que Manuel Argüello envía desde el exilio, en forma anónima. Esta y otras pistas históricas nos fueron proporcionadas por el profesor Rafael Obregón Loría.

(37) Según don Rafael Obregón sólo ha habido dos momentos en la historia de Costa Rica, en que el pueblo estuvo verdaderamente dividido: 1860 y 1948.

(38) Ricardo Fernández Guardia. Cosas y gentes de Antaño. Costa Rica: UNED, 1980; p.248. Don Ricardo fue uno de los amigos de Argüello, como lo fueron también Pío Víquez, Justo Facio, Cleto González Víquez, Aquileo Echeverría, y sobre todo José María Castro Madriz. Cuando Rubén Darío llegó a Costa Rica, se hospedó en su casa un tiempo.

(39) Bernal Díaz del Castillo. Verdadera Historia de la Conquista de la Nueva España. México: Editorial Porrúa, 1970; prólogo y primer capítulo.

(40) El símbolo de la logia masónica, un compás y una escuadra, en forma de alfiler de corbata fue donado por doña Mariana De Vars a don Rafael Obregón L. Actualmente se encuentra en el Museo Masónico.

(41) Fichero genealógico de don Rafael Obregón Loría.

(42) J. Marín Cañas. "El próximo libro..." Art. cit.

(43) M.A.M. Páginas de Historia. Costa Rica. Imprenta El Fígaro, 1898, contraportada.

(44) R. Obregón L. Los rectores de la Universidad de Santo Tornás, op. cit.

(45) A. Bonilla V. "Prólogo". En: Obras Literarias e Históricas, op. cit.; p.13.

(46) Manuel González Zeledón. "La guerra franco prusiana". En: Cuentos de Magón. Costa Rica: Imprenta Lehmann, 1968; p.159.

(47) Ibid.; p.161. 
(48) A. Bonilla V. "Prólogo", op. cit., p.13.

(49) Justo Facio. Art. Cit. Este artículo brinda datos de gran interés, pero contiene errores, por ejemplo la fecha de nacimiento -1845- que otros críticos reproducen sin pensar.

(50) Blanca Milanés es el seudónimo de Carlota Brenes Argüello, nieta de don Manuel, quien además de escritora se dedica a la enseñanza y tiene varios premios como pintora. Viven aún, además de doña Carlota, Clemencia Argüello y Dora Castro Argüello.

(51) María Pérez Yglesias. "La semiología de la productividad y la teoría del texto de Julia Kristeva". En: Revista de Filología y Lingïistica de la Universidad de Costa Rica. Vol.7, No.1 y 2, 1981; p.72. Complementario a este artículo puede consultarse "El grupo Tel Quel: una práctica textual revolucionaria”, publicado en Kañina (1981).

(52) Las nociones de texto, intertextualidad, práctica y productividad, son tomadas de la producción de Julia Kristeva, básicamente de sus textos: Semeiotiké y El tex to de la novela.

(53) A. Chase. Op. cit. p. 19.

(54) M. Castro Rawson. Op. cit.

(55) A. Chase. Op. cit.; p.19.

(56) Rodrigo Facio. Art. cit.; p.23.

(57) Confróntese M. Castro Rawson y los numerosos estudios de Francisco Ma. Núñez, sobre periodismo.

(58) M. Castro Rawson. Op. cit., p.110 y A. Bonilla V. Op. cit.: p.128.

(59) A. Bonilla V. Ibid: p.67.

(60) Ibid.; p. 109.

(61) Máximo Fernández. La lira costarricense. Costa Rica: Tipografía Nacional, 1891.

(62) Napoleón Pizarro C. Tesis sobre Manuel Argüello Mora (Borrador elaborado para optar a la Licenciatura en Filología); p. 217.

(63) Mary Clara Allison. A survey of the literature and culture of Costa Rica. Tesis para optar al PhD. University of Washington, 1952, p.287-289.

(64) Ernesto Castegnaro. Art. cit.

(65) J. Marín Cañas. Prólogo a La trinchera... Op. cit. p.7.

(66) Idem.

(67) Elizabeth Portuguéz de Bolaños. El cuento en Costa Rica. San Jose: Editorial Lehmann, 1965; p.29.

(68) M. Castro Rawson, Op. Cit., p.83.
(69) Ibid.; p.76.

(70) Ibid.; p.37.

(71) Ibid.; p.64.

(72) Ibid.; p.65.

(73) Ibid.; p.102.

(74) E. Portuguéz. Op. cit. p.29.

(75) Alvaro Quesada, en su artículo "Actitud crítica en el costumbrismo costarricense", se refiere a la actitud anecdótica y acrítica del costumbrismo tradicional, y la opone a la crítica, donde se introduce "la tragedia, la adversidad, la injusticia, en el mundo de las tradiciones patriarcales", lo mismo que "el factor social y político... para explicar ciertas formas de comportamiento". Aunque el estudioso sitúa este cambio en autores posteriores a Argüello Mora, ya en él resultan evidentes. En: Revista de Filología de la Universidad de Costa Rica. V. IX., No. 1 y 2 marzo $1981 ;$ pp.67-74.

(76) Fabián Dobles. "Estudio preliminar". En: El negro en la Literatura Costarricense. Op. cit.; p.9.

(77) Francisco Ma. Núñez, Op. cit.; p.49.

(78) N. Pizarro C. Op. Cit.; nota página 15. Las polémicas aparecen en El Fígaro. Año I, No.31-42-59-67, en 1897.

(79) M.A.M., "Las hijas del Campo". En: El Figaro, Año III, No.299, 1900, p.2.

(80) M. Castro Rawson. Op. cit., pp.72 y 414.

(81) Fco. Ma. Núñez. Op. cit.; p.49-50.

(82) Justo Facio. Art. cit.

(83) Eulogio Horta. Prólogo cit.

(84) M. Castro Rawson. Op. cit., pp.64-65.

(85) Justo Facio. Art. cit.

(86) Recuérdese que gran parte del periodismo del siglo XIX, se hace por partidismos políticos e intereses individuales; la Ilamada "profesionalización" del periodista es un fenómeno del siglo actual.

(87) E. Portuguéz. Op. cit., p.29.

(88) A. Chase. Art. cit.

(89) G.C. Hurtado. Art. cit.

(90). J, Marín Cañas. Prólogo a La Trinchera... Op. cit. p.8.

(91) J. Valdeperas. Op. cit., p.30. 
(92) Confróntese Julia Kristeva, lo semiótico y lo simbólico. En: La traversée des signes. París: Colección Tel Quel. Editions du Seuil; 1975.

(93) Fabián Dobles. Prólogo citado; p.9.

(94) Ricardo Fernández Guardia. "El ahorcado". En: LoS cuentos. Costa Rica: Imprenta Lehmann, 1971.

(95) Teño. "La leña". Recopilado por M. Castro Rawson Op. cit.

(96) Carlos Gagini. "Los negritos" En: Cuentos y otras prosas y "Los trocitos de carbón". En: Luz y bambalinas. Antología preparada por Lilia Ramos.
(97) Virginia Sandoval de Fonseca. "Letras Patrias desde la Independencia hasta hoy". En: El desarrollo Nacional en 150 años de vida independiente. Publicaciones de la Universidad de Costa Rica, 1971, p.159.

(98) Para el análisis de la ironía confróntese los trabajos de María Pérez Yglesias: "Ironía dependencia y humor en la producción significante latinoamericana". En: Revista de Filología y Lingüística de la Universidad de Costa Rica. Vol.IX, No.1 y 2, marzo 1983, y "Lenguaje popular e ironía en la producción de Hugo Díaz Jiménez”. En: Káñina ( Artes y Letras de la Universidad de Costa Rica). Vol., VII, No1, enero-julio 1983. 
